\title{
Demographics and Industry Returns
}

\author{
By Stefano DellaVigna and Joshua M. Pollet*
}

\begin{abstract}
How do investors respond to predictable shifts in profitability? We consider how demographic shifts affect profits and returns across industries. Cohort size fluctuations produce forecastable demand changes for age-sensitive sectors, such as toys, bicycles, beer, life insurance, and nursing homes. These demand changes are predictable once a specific cohort is born. We use lagged consumption and demographic data to forecast future consumption demand growth induced by changes in age structure. We find that demand forecasts predict profitability by industry. Moreover, forecast demand changes five to ten years in the future predict annual industry stock returns. One additional percentage point of annualized demand growth due to demographics predicts a 5 to 10 percentage point increase in annual abnormal industry stock returns. However, forecasted demand changes over shorter horizons do not predict stock returns. A trading strategy exploiting demographic information earns an annualized risk-adjusted return of approximately 6 percent. We present a model of inattention to information about the distant future that is consistent with the findings. We also discuss alternative explanations, including omitted risk-based factors. (JEL E21, G12, G32, J11, L11, L25)
\end{abstract}

Do demographic patterns affect stock returns across industries? While there is a substantial literature on the impact of demographic fluctuations on aggregate stock returns (Gurdip S. Bakshi and Zhiwu Chen 1994; James M. Poterba 2001; Andrew B. Abel 2003; John Geanakoplos, Michael J. P. Magill, and Martine Quinzii 2004; Andrew Ang and Angela Maddaloni 2005), there is little evidence on the effect of demographics on cross-sectional returns.

In this paper, we investigate this relationship. We analyze the impact of shifts in cohort sizes

* DellaVigna: Department of Economics, University of California, Berkeley, 549 Evans Hall, \#3880, Berkeley, CA 94729 and National Bureau of Economic Research (e-mail: sdellavi@berkeley.edu); Pollet: Department of Finance, University of Illinois at Urbana-Champaign, 8 Wohlers Hall, 1206 South Sixth Street, Champaign, IL 61820 (e-mail: pollet@uiuc.edu). We thank two anonymous referees, George Akerlof, Colin Camerer, John Campbell, David Card, Zhiwu Chen, Liran Einav, Ed Glaeser, Claudia Goldin, João Gomes, Amit Goyal, Caroline Hoxby, Gur Huberman, Michael Jansson, Lawrence Katz, David Laibson, Ronald Lee, Ulrike Malmendier, Ignacio Palacios-Huerta, Ashley Pollet, Jack Porter, James Poterba, Matthew Rabin, Joshua Rauh, Andrei Shleifer, Jeremy Stein, Geoffrey Tate, Tuomo Vuolteenaho, Michael Weisbach, Jeffrey Wurgler, seminar participants at Università Bocconi, Columbia University GSB, Emory College, UC Berkeley Haas School of Business, Northwestern University Kellogg School of Management, Harvard University, Ohio State University, Stanford on demand for different goods, and study how such shifts in demand are incorporated into stock returns.

One unusual feature characterizes demographic changes-they are forecastable years in advance. Current cohort sizes, in combination with mortality and fertility tables, generate accurate forecasts of future cohort sizes even at long horizons. Since different goods have distinctive age profiles of consumption, forecastable changes in the age distribution produce forecastable shifts in demand for various goods. These shifts in demand induce predictable changes in profitability for industries that are not perfectly competitive. Consequently, the

University Department of Economics and GSB, Università degli Studi de Trento, UC Berkeley, UI Urbana-Champaign, and participants at the NBER Behavioral Finance Program Meeting, the NBER Summer Insitute on Aging, the WFA 2004, the 2005 Rodney White Wharton Conference, and the 2004 ASSA Meetings for their comments. Jessica Chan, Fang He, Lisa Leung, Shawn Li, Fanzi Mao, Rebbecca Reed, and Terry Yee helped collect the dataset of industries. Dan Acland, Saurabh Bhargava, Justin Sydnor, and Christine Yee provided excellent research assistance. We thank Ray Fair and John Wilmoth for making demographic data available to us. For financial support, DellaVigna thanks the CEDA and the Academic Senate at UC Berkeley. Both authors thank the National Science Foundation for support through grant SES-0418206. 
timing of the stock market reaction to these predictable demand shifts provides evidence about how investors respond to predictable changes in future profitability.

We illustrate the idea of this paper with an example. Assume that a large cohort is born in 2004. This large cohort will increase the demand for school buses as of 2010. If the school bus industry is not perfectly competitive, the companies in the industry will enjoy an increase in abnormal profits in 2010. When should stock returns for these companies be abnormally high in anticipation of greater future profitability?

The timing of abnormally high returns depends on the expectations of the marginal investor. According to the standard analysis, the marginal investor foresees the positive demand shift induced by demographic changes and purchases school bus stocks in 2004. The price of school bus shares increases in 2004 until the opportunity to receive abnormal returns in the future dissipates. In this case, forecastable changes in profitability do not predict abnormal stock returns after 2004.

Alternatively, investors may be inattentive to information about future profitability that is farther than a foresight horizon of, for example, five years. (Five years is the longest horizon at which analysts make forecasts of future earnings.) In this case, stock returns in the school bus industry will not respond in 2004, but will be abnormally high in 2005, when investors start paying attention to the future shift. A third scenario is that investors overreact to the demographic information. In this case, abnormal stock returns would be high in 2004 and low in subsequent years, as realized profits fail to meet inflated expectations. In these two scenariosbut not under the standard model—demographic information available in 2004 predicts industry abnormal returns between 2005 and 2010 . Inattention implies that forecastable demand increases due to demographics predict positive abnormal returns, while overreaction implies that they predict negative returns.

This example motivates a simple test of crosssectional return predictability. In the standard model, forecastable fluctuations in cohort size do not generate predictability, because stock prices react immediately to the demographic information. If investors, instead, are inattentive to information about future profitability or overreact to such information, demographic variables predict industry asset returns.

In this paper we test whether demographic information predicts stock returns across 48 US industries over the period 1939-2003. The empirical strategy is structured to use only backward-looking information. We define industries in an effort to separate goods with different age profiles in consumption and yet cover all final consumption goods. Several goods have an obvious association with a demographic cohort. In the life cycle of consumption, books for children are followed by toys and bicycles. Later in life, individuals consume housing, life insurance, and pharmaceuticals. The life cycle ends with nursing homes and funeral homes. Other expenditure categories, like clothing, food, and property insurance, have a less obvious association with a specific age group.

In Section II, we generate the demand shifts due to demographics in three steps. In the first step, we use current cohort sizes, mortality tables, and fertility rates to forecast future cohort sizes. The forecasted cohort growth rates over the next ten years closely track the actual growth rates. The main source of variation in age-specific cohort sizes is the size of birth cohorts. Small cohorts at birth in the 1930s were followed by the large "baby-boom" cohorts in the 1950s. The small "baby-bust" cohorts of the 1960s and early 1970s gave way to larger birth cohorts in the 1980s. While demographic shifts are generally slow-moving, these fluctuations in birth cohort size generated sizeable fluctuations in cohort sizes at different ages.

In the second step, we estimate age-consumption profiles for the 48 goods in the sample. We use historical surveys on consumer expenditure from 1935-1936, 1960-1961, 1972-1973, and from the 1983-1984 Consumer Expenditure Survey. We find that: (a) consumption of most goods depends significantly on the demographic composition of the household; (b) across goods, the age profile of consumption varies substantially; and (c) for a given good, the age profile is quite stable across the surveys. These findings support the use of cohort size as a predictor of demand.

In the third step, we combine the demographic forecasts with the age profiles of consumption. The output is the good-by-good forecasted demand growth caused by demographic changes. In each year, we identify the 20 industries with 
the highest forecasted standard deviation of consumption growth. This subsample, labeled Demographic Industries, is most likely to be affected by demographic changes.

In Section III, we examine whether the forecasted consumption growth predicts profitability and stock returns for companies in the industry producing the corresponding consumption good. First, we consider the results for industry profitability. For the subset of Demographic Industries, the log accounting return on equity increases by 1.5 to 3 percentage points for each additional percentage point of contemporaneous demand growth induced by demographics. The point estimates are larger in industries with a more concentrated industrial structure, although the difference is not significant.

Next, we analyze whether forecasted demand growth due to demographics at different horizons predicts abnormal stock returns. We define shortterm demand as the forecasted annualized growth rate of consumption due to demographics over the next five years. We define long-term demand as the forecasted annualized growth rate of consumption during years 5 to 10 . In the panel regressions, we find that long-term demand growth forecasts annual stock returns. A 1 percentage point increase in the annualized long-term demand growth rate due to demographics predicts a 5 to 10 percentage point increase in abnormal industry return. The effect of short-term demand growth on returns is negative but not statistically significant. The estimates are only marginally significant with year fixed effects, suggesting that the year fixed effects absorb some of the common time-series variation in demographics. Due to the slow-moving nature of demographics, the estimates necessarily reflect a substantial uncertainty. The predictability of returns is higher in industries with above-median concentration, though not significantly so.

We also implement Fama-MacBeth regressions as an alternative approach to control for year effects. Using this methodology, we find that long-term forecasted demand growth is a significant predictor of industry returns. We also analyze the relationship between stock returns and forecasted demand growth at different horizons. We find that demand growth four to eight years ahead is the strongest predictor of returns.

Finally, we present another measure of the stock return predictability due to demographics.
We construct a zero-investment portfolio that is long in industries with high absolute and relative long-term forecasted growth and short in industries with low absolute and relative long-term forecasted growth. For the Demographic Industries, this portfolio outperforms various factor models by approximately 6 percentage points per year. A portfolio constructed using only high-concentration industries earns annualized abnormal returns of more than 8 percentage points. For a portfolio constructed using only low-concentration industries, the abnormal return is close to zero.

In Section IV, we consider explanations of the results. First, we discuss rational explanations, such as omitted risk-based factors, poor estimation of systematic risk, persistent regressors, and generated regressors. Next, we discuss behavioral explanations, such as incorrect beliefs about firm entry and exit decisions, short asset manager horizons, and neglect of slowly moving variables.

While we cannot exclude the possibility that our findings are due to an omitted risk factor, our preferred explanation is based on a model with inattentive investors, described in Section I. We assume that investors consider information about future profitability only within a horizon of $h$ years. For the periods farther into the future, investors use a combination of a parametric estimate for the long-term growth and an extrapolation from the near-term forecasts. This model embeds the standard framework as a limiting case as $h$ approaches infinity. For a horizon $h$ of approximately five years, the model of short-sighted investors matches the findings in this paper. Forecasted demand growth zero to five years ahead should not predict stock return, since this information is already incorporated into stock prices. Forecasted demand growth five to ten years ahead, instead, should predict industry stock returns, as investors gradually notice the demographic shifts more than five years ahead, and react accordingly. A foresight horizon of five years is not implausible, in light of the fact that it coincides with the horizon of analyst forecasts in the I/B/E/S data.

This paper extends the literature on the effect of demographics on corporate decisions and stock returns. Pharmaceutical companies introduce new drugs in response to predictable demand increases induced by demographics (Daron Acemoglu and Joshua Linn 2004). The paper is also related to the literature on the 
relationship between cohort size and aggregate stock market returns due to shifts in demand for financial assets. Our paper complements this literature, since we focus on the cross-sectional predictability of industry returns induced by changes in consumer demand.

N. Gregory Mankiw and David N. Weil (1989) find that contemporaneous cohort size partially explains the time-series behavior of housing prices. We generalize their approach by analyzing 48 industries and examining stock market returns where, unlike for housing prices, arbitrage should reduce predictability. While we also find evidence of predictability, stock returns are predicted by forecasted demand growth in the distant future, rather than by contemporaneous demand growth.

This paper also contributes to the literature on the role of attention allocation in economics and finance (Gur Huberman and Tomer Regev 2001; David Hirshleifer, Sonya S. Lim, and Siew H. Teoh 2004; Xavier Gabaix et al. 2006; Lin Peng and Wei Xiong 2006; DellaVigna and Pollet 2007; Brad M. Barber and Terrance Odean forthcoming). Our findings suggest that individuals may simplify complex decisions by neglecting long-term information. Our evidence is different from tests of predictability based on performance information measured by previous returns (Werner F. M. De Bondt and Richard Thaler 1985; Narasimhan Jegadeesh and Sheridan Titman 1993), accounting ratios (Eugene F. Fama and Kenneth R. French 1992; Josef Lakonishok, Andrei Shleifer, and Robert W. Vishny 1994), or earnings announcements (Ross L. Watts 1978; Victor L. Bernard and Jacob K. Thomas 1989). These variables convey information about future profitability that is not easily decomposable into short-term and long-term components.

\section{Model}

\section{A. Industrial Structure}

We consider a two-stage model (Mankiw and Michael D. Whinston 1986). In the first stage, potential entrants decide whether to pay a fixed cost $K$ to enter an industry. In the second stage, the $N$ firms that paid $K$ choose production levels $\left\{q_{n}\right\}$ in a Cournot game. The discount rate between the two periods is $R>0$. All firms have identical convex costs of production $c$ satisfying $c(0)=0, c^{\prime}()>$.0 , and $c^{\prime \prime}() \geq$.0 . We consider symmetric equilibria in the second stage where all firms choose the same quantity $q$. Hence, aggregate supply $Q$ is equal to $N q$. The aggregate demand function is $\alpha D(P)$ where $\alpha$ is a proportional demand shift capturing demographic changes. We write the inverse demand function $P=P[N q / \alpha]$ and we assume $P^{\prime}()<0,. P^{\prime \prime}($. 0 , and $P(0)>c^{\prime}(0)$. We define the accounting return on equity as profits divided by the fixed cost, $\operatorname{ROE}(q, N, \alpha)=\pi(q, N, \alpha) / K$. We also let $\theta_{S R}$ be the short-term elasticity of the gross accounting return on equity $(1+R O E)$ with respect to the demand shift $\alpha$ in the short-term, and let $\theta_{L R}$ be the analogous long-term elasticity.

In the short run (the second stage), firms observe $\alpha$ before they choose the optimal level of production $q^{*}$, but after they make the entry decision. Let $\bar{q}$ be the average production level of the $N-1$ competitors; then the second-stage maximization problem for the firm is

$$
\max _{q} \pi(q \mid N, \alpha)=\left[\frac{(N-1) \bar{q}+q}{\alpha}\right] q-c(q) .
$$

The firm's level of production and profitability changes in response to a demand shift.

In the long run, firms observe the level of demand $\alpha$ before they make the entry decision. Entry occurs until abnormal profits are zero. The equilibrium in the first stage implies that $\operatorname{ROE}\left(q^{*}, N^{*}, \alpha\right)=(1+R)$, which is independent of $\alpha .{ }^{1}$ Therefore, a change in demand $\alpha$ that is observed before the entry decision does not affect the accounting return on equity. We summarize these results in Proposition 1, which we prove in the Appendix.

PROPOSITION 1: The short-run elasticity $\theta_{S R}$ of the gross accounting return with respect to a demand shift is positive, and if marginal costs are constant $(c(q)=c q), \theta_{S R}=\pi /(\pi+K)$. The long-run elasticity $\theta_{L R}$ of the gross accounting return with respect to a demand shift is zero, $\theta_{L R}=0$.

\footnotetext{
${ }^{1}$ In this two-stage model, $R O E$ is larger than 1 , while in the data, $R O E$ is typically smaller than 0.2 . The discrepancy in magnitudes is explained by the fact that firms in the data earn profits in multiple periods, while firms in the model earn profits in just one period.
} 
To summarize, accounting returns are independent of demand changes that are observed by firms before entry (long run). Accounting returns are instead increasing in demand changes observed after entry (short run). A demand change is more likely to be observed after entry, and therefore to affect profits, if the entry decision takes longer and firms are unable to enter or exit in response to the demand shift. Hence, the responsiveness of profits to demand changes is likely to be higher for industries with higher concentration, a proxy for high barriers to entry.

\section{B. Stock Returns}

Assuming that demand shifts affect profitability, how should returns of firms in an industry respond? We consider a model in which investors can be fully attentive or short-sighted. We discuss limitations of this model below and we review some alternative explanations for our findings in Section IV.

We use log-linear approximations for stock returns (John Y. Campbell and Robert J. Shiller 1988; Campbell 1991) and for accounting return on equity (Tuomo Vuolteenaho 2002). Consider a generic expectation operator (not necessarily rational), $\hat{E}_{t}[\cdot]$, with the properties $\hat{E}_{t}\left[c a_{t+j}+\right.$ $\left.b_{t+k}\right]=c \hat{E}_{t} a_{t+j}+\hat{E}_{t} b_{t+k}$ and $a_{t}=\hat{E}_{t} a_{t}$. The unexpected return can be expressed as a change in expectations about profitability (measured by the accounting return on equity) and stock returns: ${ }^{2}$

$$
\begin{aligned}
r_{t+1}-\hat{E}_{t} r_{t+1}= & \Delta \hat{E}_{t+1} \sum_{j=0}^{\infty} \rho^{j} \text { roe } e_{t+1+j} \\
& -\Delta \hat{E}_{t+1} \sum_{j=1}^{\infty} \rho^{j} r_{t+1+j}
\end{aligned}
$$

In this expression, $r_{t+1}$ is the log return between $t$ and $t+1\left(=\log \left(1+R_{t+1}\right)\right)$, roe $_{t+1}$ is the $\log$ of the accounting return on equity between $t$ and $t$ $+1\left(=\log \left(1+R O E_{t+1}\right)\right), \rho<1$ is a constant (interpreted as a discount factor) associated with the log-linear approximation, and $\Delta \hat{E}_{t+1}[\cdot]$ $=\hat{E}_{t+1}[\cdot]-\hat{E}_{t}[\cdot]$ is the change in expectations between periods. The transversality condition for the derivation of equation (1) is $\lim _{j \rightarrow \infty} \rho^{j}\left(r_{t+1+j}\right.$

\footnotetext{
${ }^{2}$ Appendix A in DellaVigna and Pollet (2005) provides a proof.
}

$\left.-r_{t+1+j}\right)=0$, essentially, roe and $r$ cannot diverge too much in the distant future. ${ }^{3}$

Short-sighted investors have correct shortterm expectations but incorrect long-term expectations about profitability. Let $E_{t}^{*}[\cdot]$ be the expectation operator for short-sighted investors at time $t$. Similarly, let $E_{t}[\cdot]$ be the fully rational expectation operator for period $t$. Short-sighted investors have rational expectations regarding dividend growth for the first $h$ periods after $t, E_{t}^{*}$ roe $_{t+1+j}=E_{t}$ roe $_{t+1+j} \forall j<h$. For periods beyond $t+h$, they form incorrect expectations of profitability based on a constant term, $\overline{r o e}$, and an extrapolation from the expected (rational) average log return on equity for periods $t+$ $1+h-n$ to $t+h$ :

$$
\begin{aligned}
& E_{t}^{*} \text { roe }_{t+1+j}= w * \overline{r o e} \\
&+(1-w) \sum_{i=1}^{n} \frac{E_{t} r o e_{t+1+h-i}}{n} \\
& \quad \forall j \geq \mathrm{h} .
\end{aligned}
$$

Finally, we assume that short-sighted investors believe that expected log returns are characterized by a log version of the conditional capital asset pricing model (CAPM):

$$
\begin{aligned}
E_{t}^{*} r_{t+1+j}= & E_{t} r_{f, t+1+j} \\
& +E_{t} \beta_{t+j}\left(r_{m, t+1+j}-r_{f, t+1+j}\right)
\end{aligned}
$$

$$
\forall j \geq 0,
$$

where $r_{f, t+1+j}$ is the log riskless interest rate and $r_{m, t+1+j}-r_{f, t+1+j}$ is the excess log market return.

We consider three leading cases of the model. In the limiting case as $h \rightarrow \infty$, investors possess rational expectations about future profitability. If $h$ is finite and $w=1$, then investors exhibit unconditional inattention. These investors expect that the return to equity after period $t+h$ will equal a constant, $\overline{r o e}$. If $h$ is finite and $w<1$, then investors exhibit inattention with extrapolation. Investors form expectations for the return on equity after period $t+h$ with a combination

\footnotetext{
${ }^{3}$ Even if the transversality condition is not satisfied, as long as changes in expectations about the bubble are unrelated to demographic shifts, the predictions of the theory remain unchanged.
} 
of a fixed forecast, $\overline{r o e}$, and an extrapolation based on the average expected return on equity for the $n$ periods before $t+1+h$.

This model of inattention assumes that investors carefully form expectations about profitability in the immediate future, but adopt rules of thumb to evaluate profitability in the more distant future. In a world with costly information processing, these rules of thumb could be approximately optimal. The short-term forecasts embed most of the available information about profitability in the distant future. However, investors disregard useful information when they neglect long-term demographic variables. They do not realize that these demographic variables provide relatively precise forecasts of profitability even at long horizons.

Let $E_{t}^{*}[\cdot]$ characterize the expectations of a representative agent. We can substitute the short-sighted expectations, $E_{t}^{*}[\cdot]$, for the generic operator $\hat{E}_{t}[\cdot]$ in (1) and use (3) to get an expression for the "unexpected" return for shortsighted investors:

$$
\begin{aligned}
r_{t+1}-E_{t}^{*} r_{t+1}= & \Delta E_{t+1}^{*} \sum_{j=0}^{\infty} \rho^{j} \text { roe }_{t+1+j} \\
& -\Delta E_{t+1}^{*} \sum_{j=1}^{\infty} \rho^{j} r_{t+1+j} \\
= & \Delta E_{t+1} \sum_{j=0}^{h-1} \rho^{j} \text { roe }_{t+1+j} \\
& +\rho^{h}\left[E_{t+1} \text { roe }_{t+1+h}-w \overline{r o e}\right. \\
& \left.\quad-(1-w) \sum_{i=1}^{n} \frac{E_{t} r o e_{t+1+h-i}}{n}\right]
\end{aligned}
$$$$
+(1-w)
$$$$
\times \sum_{j=h+1}^{\infty} \rho^{j}\left[\sum_{i=1}^{n} \frac{E_{t+1} \text { roe }_{t+2+h-i}}{n}\right.
$$

$$
\left.-\sum_{i=1}^{n} \frac{E_{t} r o e_{t+1+h-i}}{n}\right]
$$$$
-\Delta E_{t+1} \sum_{j=1}^{\infty} \rho^{j}\left(r_{f, t+1+j}\right.
$$$$
+\beta_{t+j}\left(r_{m, t+1+j}\right.
$$

The unexpected return, $r_{t+1}-E_{t+1}^{*} r_{t+1}$, depends on the value of the return on equity only up to period $t+1+h$; the later periods are not incorporated, since investors are short-sighted.

We define the abnormal or risk-adjusted return $a r_{t+1}$ to be consistent with the log version of the conditional CAPM:

$$
a r_{t+1}=r_{t+1}-r_{f, t+1}-\beta_{t}\left(r_{m, t+1}-r_{f, t+1}\right) .
$$

Taking conditional rational expectations at time $t$ (using $E_{t}[\cdot]$ ) and applying the law of iterated expectations, we derive the expected abnormal return $E_{t} a r_{t+1}$ from the perspective of the fully rational investor:

$$
\begin{aligned}
E_{t} \operatorname{ar}_{t+1}= & \rho^{h} w\left(E_{t} \text { roe }_{t+1+h}-\overline{\text { roe }}\right) \\
& +\rho^{h}(1-w) \\
& \times \sum_{i=1}^{n} E_{t}\left[\text { roe }_{t+1+h}-\operatorname{roe}_{t+1+h-i}\right] / n \\
& +\frac{\rho^{h+1}}{1-\rho} \frac{(1-w)}{n} \\
& \times E_{t}\left[\text { roe }_{t+1+h}-\operatorname{roe}_{t+1+h-n}\right] .
\end{aligned}
$$

The expected return between time $t$ and time $t+$ 1 depends on the sum of three terms. For rational investors $(h \rightarrow \infty)$, all terms converge to zero (given $\rho<1$ ) and we obtain the standard result of unforecastable returns. For investors with unconditional inattention ( $h$ finite and $w=1$ ), only the first term is relevant: $E_{t} a r_{t+1}=\rho^{h}\left(E_{t}\right.$ roe $_{t+1+h}-$ $\overrightarrow{r o e})$. Returns between year $t$ and year $t+1$ are predictable using the difference between the expected return on equity $h+1$ years ahead and the constant $\overline{r o e}$. For inattentive investors with extrapolation ( $h$ finite and $w=0$ ), only the last two terms are relevant. Abnormal returns depend positively on the expected return on equity $h+$ 1 years ahead and negatively on the expected return on equity in the previous $n$ years (because these agents rely too heavily on the short-term expectations about roe). In general, for inattentive investors ( $h$ finite), stock returns between time $t$ and $t+1$ are forecasted positively by the expected return on equity $h+1$ years ahead and negatively by the expected return on equity for the $n$ years before $t+1+h$. 
The intuition is as follows. Between years $t$ and $t+1$, investors update their expectations by incorporating the expected profitability in period $t+1+h$, which was previously ignored. This information replaces the earlier forecast that was created using $\overline{r o e}$ and the expected return on equity between years $t+1+h-n$ and $t+h$. Expected returns are an increasing function of the update about future profitability. This update depends positively on expected profitability in period $t+1+h$ and negatively on $\overline{r o e}$ and on expected profitability between $t+$ $1+h-n$ and $t+1+h$.

We showed above that the accounting return on equity responds to contemporaneous demand changes if the changes are not known before the entry decision. Under additional conditions, the relationship between the log return on equity and the $\log$ of the demand shift $\alpha$ is linear (equation (12)): roe $_{t+1+j}=\phi+\theta \log \left(\alpha_{t+1+j}\right)+z_{t+1+j}$. The parameter $\theta$ is the elasticity of accounting return on equity with respect to demand shifts; in the presence of very high barriers to entry, we expect $\theta=\theta_{S R}>0$; with no barriers to entry, we expect $\theta=\theta_{L R}=0$. In the following, we consider an intermediate case with $\theta>0$. We decompose the log demand shift in period $t+1+j, \log \left(\alpha_{t+1+j}\right)$, into the change in $\log$ demand due to demographics, $\Delta c_{t+1+j}=$ $\log \left(C_{t+1+j}\right)-\log \left(C_{t+j}\right)$, and the residual change in log demand, $\omega_{t+1+j}$, and write

$$
\operatorname{roe}_{t+1+j}=\phi+\theta \Delta c_{t+1+j}+v_{t+1+j},
$$

where $v_{t+1+j}=\theta \omega_{t+1+j}+z_{t+1+j}$. For simplicity, we assume that $E_{t+j} v_{t+1+j}=0$ for any $j \geq$ 0 . Substituting expression (6) into equation (5) we obtain

$$
\begin{aligned}
E_{t} a r_{t+1}= & \eta+\rho^{h} w \theta E_{t} \Delta c_{t+1+h} \\
& +\rho^{h}(1-w) \theta \\
& \times \sum_{i=1}^{n} E_{t}\left[\Delta c_{t+1+h}-\Delta c_{t+1+h-i}\right] / n \\
& +\frac{\rho^{h+1}}{1-\rho} \frac{(1-w)}{n} \theta \\
& \times E_{t}\left[\Delta c_{t+1+h}-\Delta c_{t+1+h-n}\right],
\end{aligned}
$$

where $\eta$ is a constant equal to $\rho^{h} w(\phi-\overline{r o e}){ }^{4}$ Using equation (7), we derive Predictions 1-3.

PREDICTION 1: If investors are rational $(h \rightarrow$ $\infty)$, the expected abnormal return, $E_{t} a r_{t+1}$, is independent of expected future demand growth, $E_{t} \Delta c_{t+1+j}$, for any $j \geq 0$.

PREDICTION 2: If investors are inattentive ( $h$ finite), the expected abnormal return, $E_{t} a r_{t+1}$, is positively related to expected future demand growth $h+1$ periods ahead, $E_{t} \Delta c_{t+1+h}$. Moreover, $\partial E_{t} a r_{t+1} / \partial E_{t} \Delta c_{t+1+h}=\rho^{h} \theta[1+(1-$ w) $\rho /((1-\rho) n)]$.

PREDICTION 3: If investors are inattentive with extrapolation ( $h$ finite and $w<1$ ), the expected abnormal return $E_{t} a r_{t+1}$ is negatively related to expected future demand growth less than $h+1$ periods ahead, $E_{t} \Delta c_{t+1+h-i}$ for all $1 \leq i \leq n$.

Under the null hypothesis of rational investors, forecastable demographic shifts do not affect abnormal stock returns (Prediction 1). Under the alternative hypothesis of inattention, instead, forecastable demand growth $h+$ 1 periods ahead predicts abnormal stock returns (Prediction 2). This prediction also links the magnitude of forecastability to the sensitivity of accounting return on equity to demand changes $(\theta)$; the value of $\partial E_{t} a r_{t+1} / \partial E_{t} \Delta c_{t+1+h}$ may be as small as $\rho^{h} \theta$ (for $w=1$ ) or as large as $\rho^{h} \theta[1+\rho /(1-\rho)]$ (for $w=0$ and $n=1$ ). Finally, if investors extrapolate to some extent using short-term expectations (for $w<1$ ), then demand growth less than $h+1$ periods ahead forecasts abnormal returns negatively (Prediction 3). This occurs because investors overreact to information in the near future. (We should note that the negative relationship due to extrapolation is smaller in absolute magnitude than the positive relationship between $E_{t} a r_{t+1}$ and $\left.E_{t} \Delta c_{t+1+h}.\right)$

In this analysis, we make two key assumptions. First, we consider a representative agent

\footnotetext{
${ }^{4}$ Expression (6) for roe is consistent with the transversality condition used to derive equation (7). A simple set of sufficient conditions for the limiting behavior of roe and $r$ guarantees that the transversality condition is satisfied. A proof is available from the authors upon request.
} 
model. An alternative model would consider a model of interactions between inattentive investors and rational agents in the presence of limited arbitrage (J. Bradford DeLong et al. 1990; Shleifer 2000). We also make the unrealistic assumption that all investors have a horizon of exactly $h$ periods. If the horizon, instead, varied between $h$ and $h+\tilde{H}$, industry abnormal returns would be forecastable using demand growth rates due to demographics between years $t+h$ and $t+h+\tilde{H}$. The empirical specification in Section IIIB acknowledges that horizons may vary and that the precision of the data does not permit separate estimates of each relationship between returns and expected consumption growth at a specific horizon. Therefore, we form two demand growth forecasts, one for shortterm growth between $t$ and $t+5$, and one for long-term growth between $t+5$ and $t+10$.

\section{Demographics and Demand Shifts}

To construct demographic-based forecasts of demand growth by good, we combine demographic forecasts and estimates of age patterns in the consumption data.

\section{A. Demographic Forecasts}

We combine data sources on cohort size, mortality, and fertility rates to form forecasts of cohort sizes (additional details are in Appendix B1). All the demographic information is disaggregated by gender and one-year age groups. The cohort size data are from the Current Population Reports, Series P-25 (US Department of Commerce, Bureau of the Census). The cohort size estimates are for the total population of the United States, including armed forces overseas. We use mortality rates from period life tables for the years 1920-2000 from Life Tables for the United States Social Security Area 1900-2080. Finally, we take age-specific birth rates from Robert Heuser (1976) and update this information using the Vital Statistics of the United States: Natality (US Department of Health and Human Services).

We use demographic information available in year $t$ to forecast the age distribution by gender and one-year age groups for years $u>$ $t$. We assume that fertility rates for the years $u$ $>t$ equal the fertility rates for year $t$. We also assume that future mortality rates equal mortality rates in year $t$, except for a backward-looking percentage adjustment described in Appendix A. Using cohort size in year $t$ and the forecasts of future mortality and fertility rates, we form preliminary forecasts of cohort size for each year $u>t$. We adjust these preliminary estimates for net migration using a backward-looking procedure also described in Appendix A.

Using these procedures, we define $\hat{A}_{g, u \mid t}=$ $\left[\hat{A}_{g, 0, u \mid t}, \hat{A}_{g, 1, u \mid t}, \hat{A}_{g, 2, u \mid t}, \ldots\right]$ as the future forecasted age distribution. Each element, $\hat{A}_{g, j, u \mid t}$, is the number of people of gender $g$ alive at $u$ with age $j$ forecasted using demographic information available at $t$. The actual cohort size of gender $g$ alive at $u$ with age $j$ is $A_{g, j, u}$. Figure 1A plots the actual series of population age 10-14 over the years 1930-2002, as well as three forecasts as of 1935, 1955, and 1975. The forecasts track actual cohort sizes well, except for forecasts more than 15 years ahead that depend heavily on predicting future cohort sizes at birth.

The time-series behavior of the cohort size age 10-14 can be articulated in four periods: (a) the cohort size decreases between 1935 and 1945, reflecting the low fertility of the 1930s; (b) it increases substantially between 1945 and 1970, reflecting the higher fertility rates of the 1940s and particularly during the years 1947-1960 (the baby boom); (c) it decreases between 1970 and 1985, due to lower fertility rates in the years following 1960 (the baby bust); (d) it increases again after 1985, in response to the impending parental age of the baby boom cohort. The swings in the cohort size of the young provide substantial demand shifts to the goods purchased by this group of young people, such as toys, bicycles, and books K-12.

Panels B, C, and D of Figure 1 present the corresponding patterns for the age groups 30$34,50-54$, and 70-74. The cohort size age 3034 follows similar time-series patterns as the cohort age 10-14, shifted forward by approximately 20 years. The cohort sizes of the older cohorts vary less; in particular, the cohort age 70-74 grows in a fairly uniform manner over time. Demographic shifts induce the most variation in demand for goods consumed by the young and by young adults. This specific feature of demographic changes differentiates our paper from the literature about the relationship between demographics and the equity premium. 
A. Forecasted and actual population ages 10-14

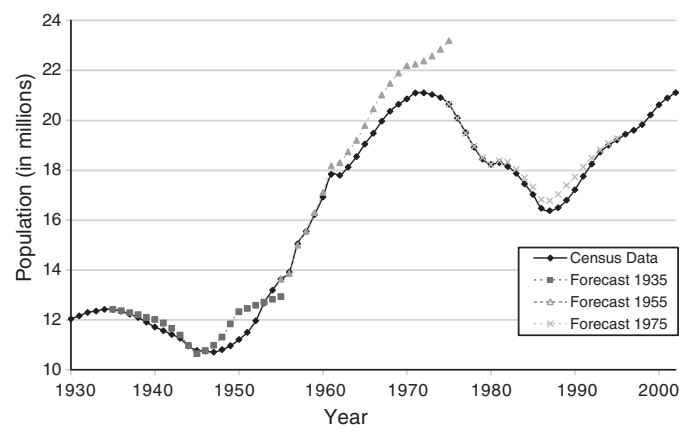

A. Forecasted and actual population ages 50-54

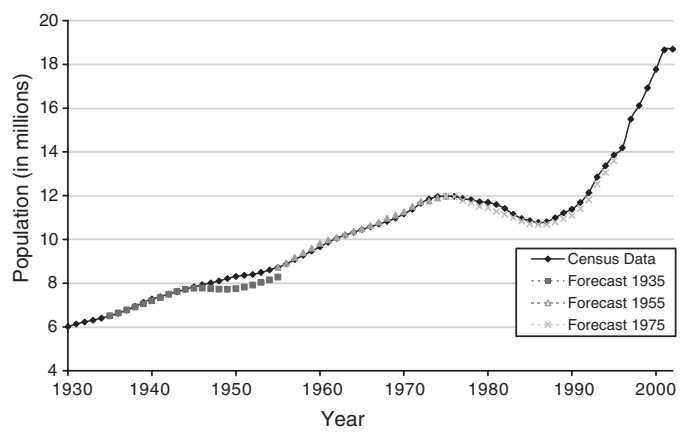

B. Forecasted and actual population ages 30-34

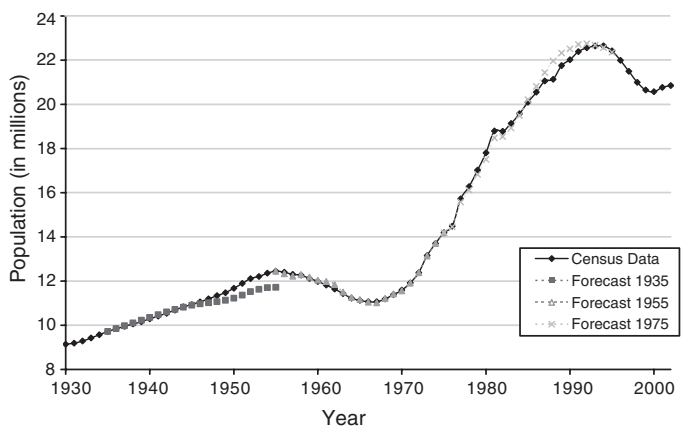

C. Forecasted and actual population ages 70-74

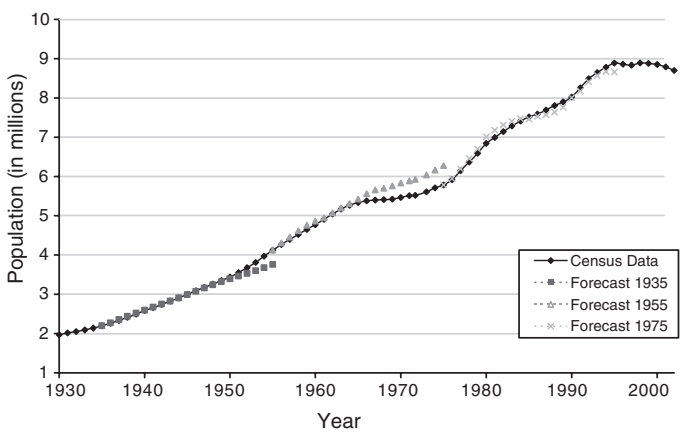

FIGURE 1

Notes: In the figure, panels A, B, C, and D display time series of actual and forecasted cohort size for the age groups 10-14, 30-34, 50-54, and 70-74. Each panel shows the actual time series as well as three different 20-year forecasts, made as of 1935,1955 , and 1975 .

In this literature, aggregate risk-bearing capacity is affected by the share of older people.

Table 1 evaluates the precision of our demographic forecasts at the same horizons employed in our tests of return predictability: a short-term forecast over the next five years and a longterm forecast five to ten years in the future. In column 1, we regress the actual population growth rate over the next five years, $\log A_{g, j, t+5}$ - $\log A_{g, j, t}$, on the forecasted growth rate over the same horizon, $\log \hat{A}_{g, j, t+5 \mid t}-\log \hat{A}_{g, j, t \mid t}$. Each observation is a (gender) $\times$ (one-year age group) $\times$ (year of forecast) cell; this specification includes all age groups and years between 1937 and 2001. The $R^{2}$ of 0.836 and the regression coefficient close to one indicate that the forecasts are quite accurate. The precision of the forecasts is comparable for the cohorts between 0 and 18 years of age $\left(R^{2}=0.819\right.$, column 2$)$ but lower for the cohorts between 65 and 99 years of age $\left(R^{2}=0.571\right.$, column 3$)$. The precision of the long-term forecasts (five to ten years in the future) is only slightly inferior to the precision of the short-term forecasts for the total sample (column 4) and for the 65+ age group (column $6)$. The accuracy of these forecasts is substantially lower, however, for the cohorts up to age 18 (column 5) because a large fraction of the forecasted cohorts are unborn as of year $t$.

Overall, our forecasts predict cohort size growth quite well over the horizons of interest. They also closely parallel publicly available demographic forecasts, in particular the official Census Bureau forecasts created using 2000 census data. In column 7 , we regress the official forecast for population growth for the next five years, $\log \hat{A}_{g, j, 2005 \mid 2000}^{C}-\log \hat{A}_{g, j, 2000 \mid 2000 \text {, on our }}^{C}$ forecast, $\log \hat{A}_{g, j, 2005 \mid 2000}-\log \hat{A}_{g, j, 2000 \mid 2000}$, for 
Table 1-Predictability of Population Growth Rates by Cohort

Dependent variable:

Actual population growth for each cohort

Census projection of population growth

\begin{tabular}{|c|c|c|c|c|c|c|c|c|}
\hline & \multicolumn{3}{|c|}{0 to 5 years ahead } & \multicolumn{3}{|c|}{5 to 10 years ahead } & \multirow{2}{*}{$\begin{array}{c}0 \text { to } 5 \text { yrs } \\
\text { Ages } 0-99 \\
\text { (7) }\end{array}$} & \multirow{2}{*}{$\begin{array}{c}5 \text { to } 10 \text { yrs } \\
\text { Ages } 0-99 \\
(8)\end{array}$} \\
\hline & $\begin{array}{l}\text { Ages 0-99 } \\
\text { (1) }\end{array}$ & $\begin{array}{c}\text { Ages } 0-18 \\
(2)\end{array}$ & $\begin{array}{c}\text { Ages } 65+ \\
\text { (3) }\end{array}$ & $\begin{array}{c}\text { Ages } 0-99 \\
\text { (4) }\end{array}$ & $\begin{array}{c}\text { Ages } 0-18 \\
(5)\end{array}$ & $\begin{array}{c}\text { Ages } 65+ \\
(6)\end{array}$ & & \\
\hline Constant & $\begin{array}{l}0.004 \\
(0.0005)^{* * * *}\end{array}$ & $\begin{array}{l}-0.001 \\
(0.0011)^{* * * *}\end{array}$ & $\begin{array}{l}0.023 \\
(0.0019)^{* * *}\end{array}$ & $\begin{array}{l}0.012 \\
(0.0007)^{* * * *}\end{array}$ & $\begin{array}{l}0.004 \\
(0.0021)^{* *}\end{array}$ & $\begin{array}{l}0.034 \\
(0.0020)^{* * *}\end{array}$ & $\begin{array}{l}-0.004 \\
(-0.006)\end{array}$ & $\begin{array}{l}-0.009 \\
(0.0048)^{*}\end{array}$ \\
\hline $\begin{array}{l}\text { Forecasted population } \\
\text { growth: } 0 \text { to } 5 \mathrm{yrs}\end{array}$ & $\begin{array}{l}0.916 \\
(0.0037)^{* * * *}\end{array}$ & $\begin{array}{l}0.916 \\
(0.0086)^{* * * *}\end{array}$ & $\begin{array}{l}0.799 \\
(0.0122)^{* * *}\end{array}$ & & & & $\begin{array}{l}1.129 \\
(0.0494)^{* * * *}\end{array}$ & \\
\hline $\begin{array}{l}\text { Forecasted population } \\
\text { growth: } 5 \text { to } 10 \mathrm{yrs}\end{array}$ & & & & $\begin{array}{l}0.849 \\
(0.0053)^{* * * *}\end{array}$ & $\begin{array}{l}0.710 \\
(0.0172)^{* * * *}\end{array}$ & $\begin{array}{l}0.728 \\
(0.0138)^{* * *}\end{array}$ & & $\begin{array}{l}1.089 \\
(0.0385)^{* * * *}\end{array}$ \\
\hline$R^{2}$ & 0.836 & 0.819 & 0.571 & 0.701 & 0.423 & 0.494 & 0.725 & 0.801 \\
\hline$N$ & $N=11800$ & $N=2508$ & $N=3220$ & $N=10800$ & $N=2318$ & $N=2870$ & $N=200$ & $N=200$ \\
\hline
\end{tabular}

Notes: Reported coefficients from the regression of actual population growth rates on our forecasted growth rates in columns 1 through 6. In columns 7 through 9 , we report coefficients from the regression of census projections of population growth rate as of 2000 on our forecasted growth rates. In columns 1 through 3 and in column 7, the growth rates refer to the next five years. In columns 4 through 6 and in column 8 , the growth rates refer to the period between five and ten years ahead. The regression specification is $y_{i t}=a+b x_{i t}+e_{i t}$, where $t$ is a year ranging from 1935 to 2001 and $i$ is an age-gender observation within the relevant age range indicated at the top of each column. Age is defined by one-year cells. The OLS standard errors are in parentheses. Actual population sizes for both sexes between the ages 0 and 99 are from the P-25 Series from the Current Population Reports provided by US Census. Forecasted population sizes for each age-gender observation are calculated using the previous year's P-25 data and mortality rates from the period life table at the beginning of the decade from Life Tables for the United States Social Security Area 1900-2080. The forecasted number of newborns is calculated by applying birth rates from the previous year to the forecasted age profile of the female population. The census projection of population growth rate is calculated using data from the census Web site. The actual and estimated growth rates are defined as the difference in the $\log$ population for a particular age-gender pair.

*** Significant at, or below, 1 percent.

** Significant at, or below, 5 percent.

* Significant at, or below, 10 percent.

age groups between 0 and 99 . This regression has an $R^{2}$ of 0.725 and a coefficient estimate slightly greater than one. Column 8 reports similarly precise results for forecasted demographic growth between 2005 and 2010 .

\section{B. Age Patterns in Consumption}

Unlike demographic information, exhaustive information on consumption of different goods is available only after 1980 . For the previous years, we use the only surveys available in an electronic format: the Study of Consumer Purchases in the United States, 1935-1936, the Survey of Consumer Expenditures, 1960-1961, and the Survey of Consumer Expenditures, 1972-1973. ${ }^{5}$ We combine these three early surveys with the

\footnotetext{
${ }^{5}$ Dora Costa (1999) discusses the main features of these surveys.
}

1983-1984 cohorts of the ongoing Consumer Expenditure Survey. ${ }^{6}$

We cover all major expenditures on final goods. The selected level of aggregation attempts to distinguish goods with different age-consumption profiles. For example, within the category of alcoholic beverages, we separate beer and wine from hard liquor expenditures. Similarly, within insurance, we distinguish among health, property, and life insurance expenditures. We attempt to define these categories in a consistent way across the survey years. ${ }^{7}$

\footnotetext{
${ }^{6}$ The cohorts in the Survey of Consumer Expenditures are followed for four quarters after the initial interview. Consequently, the data for the fourth cohort of 1984 includes 1985 consumption data.

${ }^{7}$ Appendix B2 provides additional information about the consumption data.
} 
To illustrate the age profile of selected goods, we use kernel regressions of household annual consumption on the age of the head of household $^{8}$. Figure 2A plots normalized ${ }^{9}$ expenditure on bicycles and drugs for the 1935-1936, 1960-1961, 1972-1973, and 1983-1984 surveys. Across the two surveys, the consumption of bicycles peaks between the ages of 35 and 45 . At these ages, the heads of household are most likely to have children between the ages of 5 and 10. The demand for drugs, instead, is increasing with age, particularly in the later surveys. Older individuals demand more pharmaceutical products. The differences in age profiles occur not just between goods targeted at young generations (e.g., bicycles) and goods targeted to the old (e.g., drugs), but also within broad categories, such as alcoholic beverages (Figure $2 \mathrm{~B})$. For each of the surveys, the peak of the age profile of consumption for beer and wine occurs about 20 years earlier than the peak of the profile for hard liquor. In another example, purchases of large appliances peak at 25-30 years of age, perhaps at the time of first house purchase, while purchases of small appliances are fairly constant across the years 25-50 (results not shown).

This evidence supports three general statements. First, the amount of consumption for each good depends significantly on the age of the head of household. Second, these age patterns vary substantially across goods. Some goods are consumed mainly by younger household heads (child care and toys), some by heads in middle age (life insurance and cigars), others by older heads (cruises and nursing homes). Third, the age profile of consumption for a given good is quite stable across time. For example, the expenditure on furniture peaks at ages 25-35, whether we consider the 1935-1936, the 1960-1961, the 1972-1973, or the 1983-1984 cohorts. Taken as a whole, the evidence suggests that changes in age structure of the population have the power to influence consumption demand in a substantial and consistent manner.

\footnotetext{
${ }^{8}$ We use an Epanechnikov kernel with a bandwidth of five years of age for all the goods and years.

${ }^{9}$ For each survey-good pair we divide age-specific consumption for good $k$ by the average consumption across all ages for good $k$.
}

In order to match the consumption data with the demographic data, we transform the household-level consumption data into individual-level information. We use the variation in demographic composition of the families to extract individual-level information-consumption of the head, of the spouse, and of the children-from household-level consumption data. We use an OLS regression in each of the four cross sections. We denote by $c_{i, k, t}$ the consumption by household $i$ of good $k$ in year $t$ and by $H_{i, t}$ a set of indicator variables for the age groups of the head of household $i$ in year $t$. In particular, $H_{i, t}=\left[H_{18, i, t}, H_{27, i, t}, H_{35, i, t}, H_{45, i, t}, H_{55, i, t}\right.$, $\left.H_{65, i, t}\right]$, where $H_{j, i, t}$ is equal to one if the head of household $i$ in year $t$ is at least as old as $j$ and younger than the next age group. For example, if $H_{35, i, t}=1$ then the head of household $i$ is aged 35 to 44 in year $t$. The variable $H_{65, i, t}$ indicates that the age of the head of household is greater than or equal to 65 . Similarly, let $S_{i, t}$ be a set of indicator variables for the age groups of the spouse. Finally, we add discrete variables $O_{i, t}$ $=\left[O_{0, i, t}, O_{6, i, t}, O_{12, i, t}, O_{18, i, t}, O_{65, i, t}\right]$ that count the total number of other individuals (children or old relatives) living with the family in year $t$. For instance, if $O_{0, i, t}=2$, then two children age zero to five live with the family in year $t$.

The regression specification is

$$
c_{i, k, t}=B_{k, t} H_{i, t}+\Gamma_{k, t} S_{i, t}+\Delta_{k, t} O_{i, t}+\varepsilon_{i, k, t} .
$$

This OLS regression is estimated separately for each good $k$ and for each of the four cross sections $t$. The purpose is to obtain estimates of annual consumption of good $k$ for individuals at different ages. For example, the coefficient $B_{35 \text {,cars, } 1960}$ is the average total amount that a (single) head age 35 to 44 spends on cars in 1960. ${ }^{10}$

\footnotetext{
${ }^{10}$ We do not include the set of spouse variables in the 1935-1936 survey (only married couples were interviewed) and in the 1960-1961 survey (the age of the spouse was not reported). Since the size of sample for the 1935-1936 survey is only a third to a half as large as the sample sizes for the other surveys, for this survey we use broader age groups for the head-of-household variables: $18,35,50$, and 65 . We obtain similar findings throughout the paper if we do not use the spouse coefficients for any survey or if we use the broader age groups for all surveys.
} 


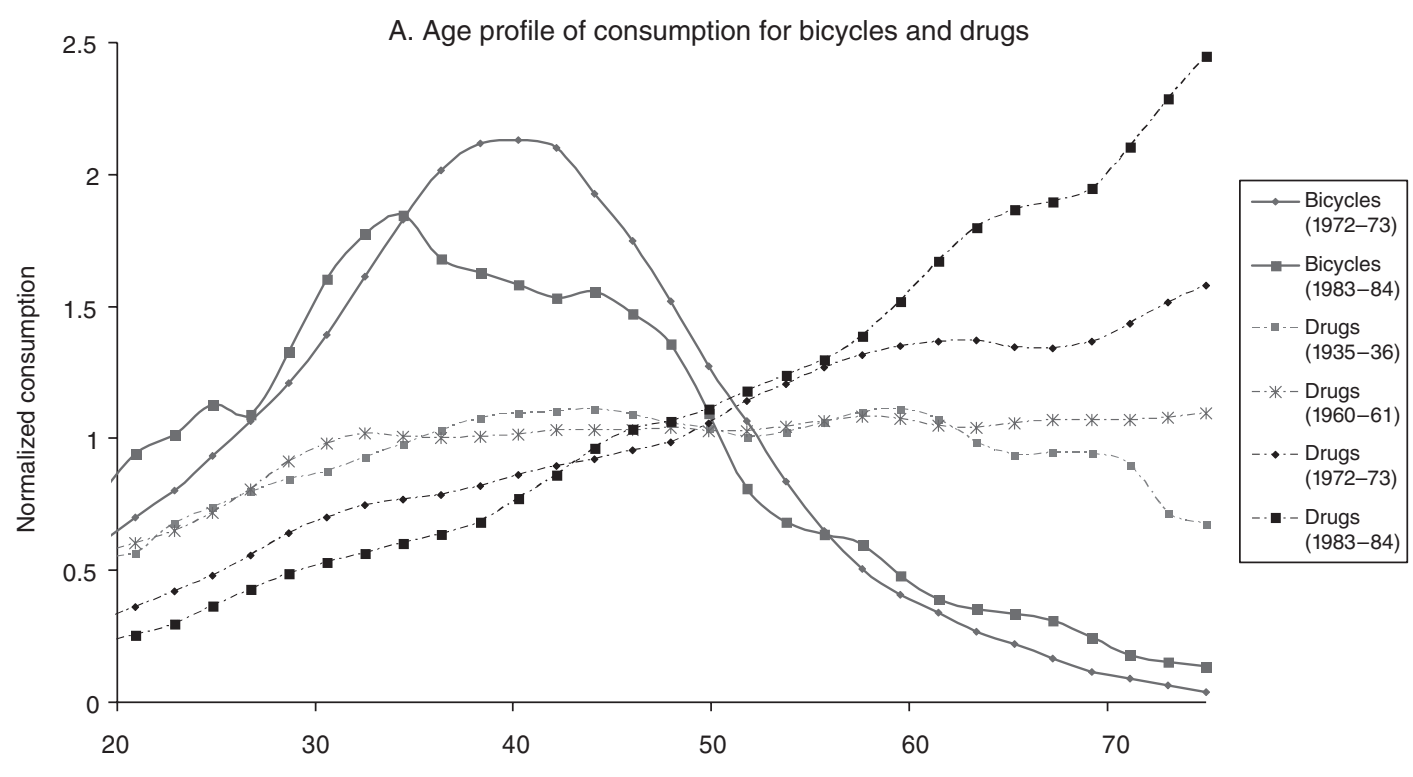

Age for head of household

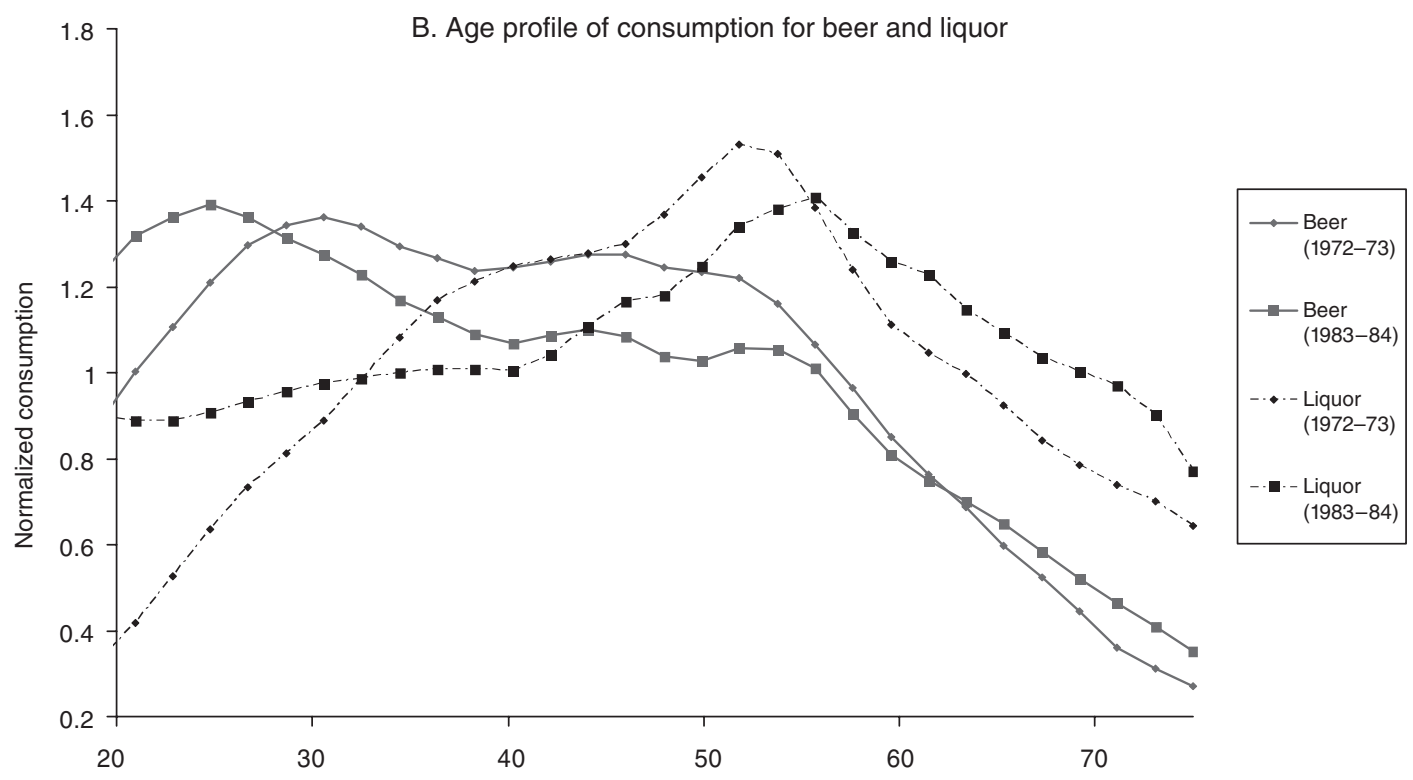

Age for head of household

FIGURE 2

Notes: Figures 2A and 2B display kernel regressions of normalized household consumption for each good as a function of the age for the head of the household. The regressions use an Epanechnikov kernel and a bandwidth of five years. Each different line for a specific good uses an age-consumption profile from a different consumption survey. Expenditures are normalized so that the average consumption for all ages is equal to one for each survey-good pair. For bicycles and alcohol consumption, no data are available for the 1935-1936 and the 1960-1961 surveys. 


\section{Demand Forecasts}

We combine the estimated age profiles of consumption with the demographic forecasts in order to forecast demand for different goods. For example, consider a forecast of toy consumption in 1975 made as of 1965. For each age group, we multiply the forecasted cohort sizes for 1975 by the age-specific consumption of toys estimated on the most recent consumption data as of 1965 , that is, the 1960-1961 survey. Next, we aggregate across all the age groups to obtain the forecasted overall demand for toys for 1975 .

Formally, let $\hat{A}_{g, u \mid t}^{b}$ be the aggregation of $\hat{A}_{g, u \mid t}$ into the same age bins that we used for the consumption data. For example, $\hat{A}_{f, 35, u \mid t}^{b}$ is the number of females age 35 though 44 forecasted to be alive in year $u$ as of year $t$. We combine the forecasted age distribution $\hat{A}_{g, u \mid t}^{b}$ with the agespecific consumption coefficients $B_{k, t}, \Gamma_{k, t}$, and $\Delta_{k, t}$ for good $k$. In order to perform this operation, we estimate the shares $h_{g, j, t}, s_{g, j, t}$, and $o_{g, j, t}$ of people in the population for each age group $j$. For instance, $h_{f, 35, t}$ is the number of female heads 35-44 divided by the total number of females age 35-44 in the most recent consumption survey prior to year $t$. We obtain a demographic-based forecast at time $t$ of the demand for good $k$ in year $u$ which we label $\hat{C}_{k, u \mid t}$ :

$$
\begin{aligned}
\hat{C}_{k, u \mid t}= & \sum_{g \in\{f, m\}} \sum_{j \in\{0,6,12,18, \ldots, 65\}} \hat{A}_{g, j, s \mid t}^{b} \\
& \times\left(h_{g, j, t} B_{j, k, t}+s_{g, j, t} \Gamma_{j, k, t}+o_{g, j, t} \Delta_{j, k, t}\right) .
\end{aligned}
$$

The coefficients $B, \Gamma$, and $\Delta$ in this expression are estimated using the most recent consumption survey prior to year $t$ with information on good $k$. This forecast implicitly assumes that the tastes of consumers for different products depend on age and not on cohort of birth. We assume that individuals age 45 in 1975 consume the same bundles of goods that individuals age 45 consumed in 1965. By construction, we hold the prices of each good constant at its level in the most recent consumption survey prior to year $t .^{11}$

11 See Appendix B2 for information on the calculation of forecasted demand growth rates for construction machinery and residential construction.
Figure 3 shows the results of the consumption forecasts for three subcategories of the general book category-books for K-12 schools, books for higher education, and other books (mostly fiction). We plot the predicted cumulative demand growth from 1975 to 1995 using the information available in 1975 from the expression $\ln \hat{C}_{k, u \mid 1975}$ $-\ln \hat{C}_{k, 1975 \mid 1975}$ for $u=1975,1976, \ldots, 1995$. For each of the three goods, we produce forecasts using the age-consumption profiles estimated from the three consumption datasets that record detailed expenditure for books, the 1935-1936, 1972-1973, and 1983-1984 datasets. The demand for $\mathrm{K}-12$ books is predicted to experience a decline as the baby-bust generation continues to enter schools, followed by an increase. The demand for college books is predicted to increase and then decline, as the cohorts entering college are first large (baby boom) and then small (baby bust). Finally, the demand for other books, which is mostly driven by adults between the ages of 30 and 50, is predicted to grow substantially as members of the baby-boom generation gradually reach these ages. These patterns do not depend on the year of expenditure survey (1935-1936, 1972-1973, or 1983-1984) used to estimate the age-consumption profile for each category. In particular, the projections using the more recent consumption surveys (1972-1973 and 1983-1984) are essentially identical for two of the three categories.

While we cannot present the same detailed information for all goods, we report the consumption forecasts at three points in time. Columns 2, 4, and 6 of Table 2 summarize the five-year predicted growth rate due to demographics, $\ln \hat{C}_{k, t+5 \mid t-1}-\ln \hat{C}_{k, t \mid t-1}$, respectively for years $t=1950, t=1975$, and $t=2000$. The bottom two rows present the mean and the standard deviation across goods of this measure. In 1950, child-related expenditures are predicted to grow quickly due to the boom in births starting in 1947. Demand for housing-related goods is relatively low due to the small size of cohorts born in the 1930s. In 1975, the demand for child care and toys is low due to the small size of the baby-bust generation. The demand for most adult-age commodities is predicted to grow at a high rate (1.5-2 percent a year) due to the entry of the baby-boom generation into prime consumption age. In 2000, the demand for childrelated commodities is relatively low. The aging 


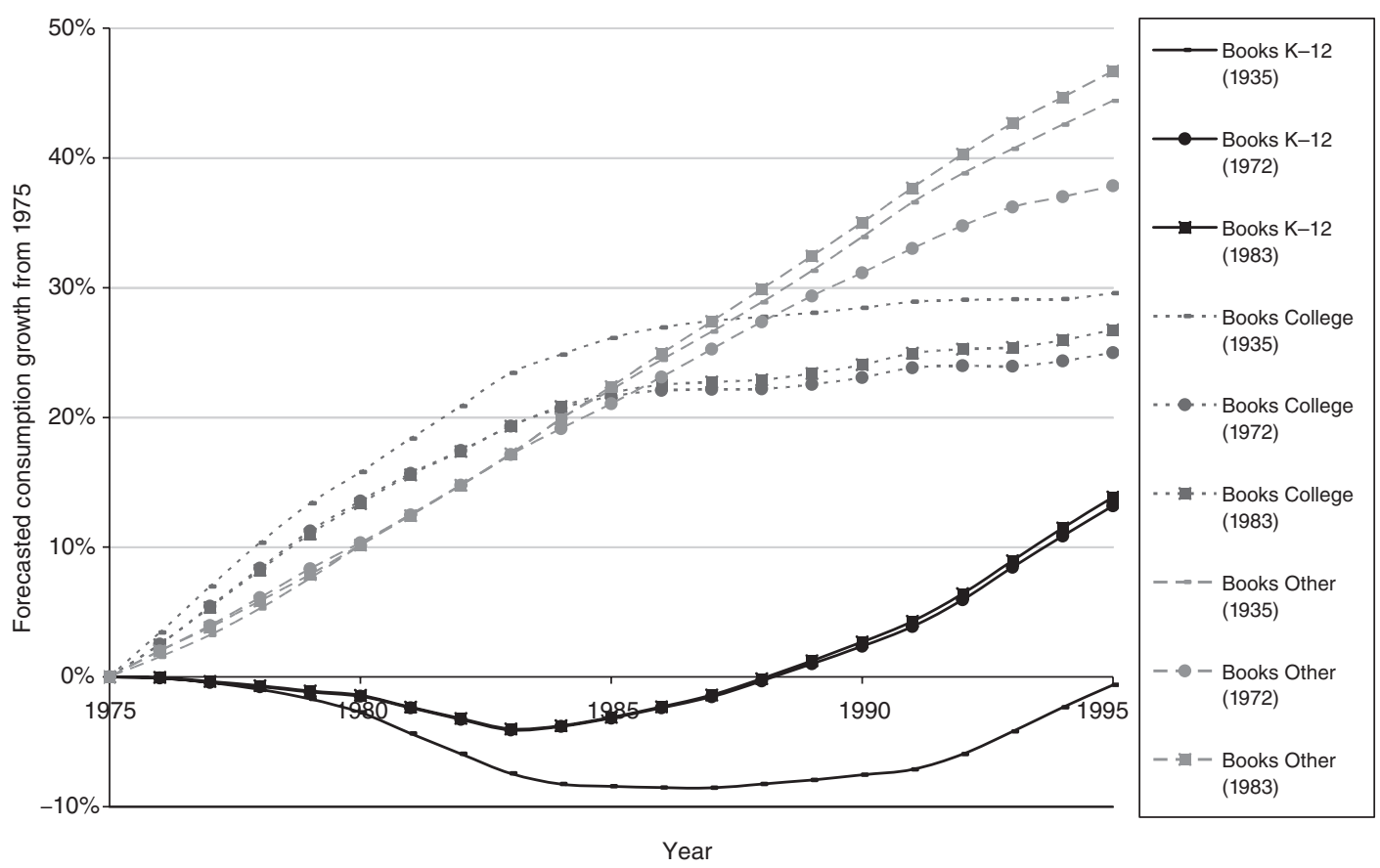

Figure 3. Forecasted Cumulative Demand Growth for Books

Notes: Figure 3 displays the predicted consumption growth due to forecasted demographic changes for three subcategories of books: books for $\mathrm{K}-12$ schools, books for higher education, and other books (mainly fiction). The forecasts are computed combining the demographic information of year 1975 and age-consumption profiles for the 1935-1936, 1972-1973, and 1983-1984 consumption surveys. Each distinct line for a good uses an age-consumption profile from a different dataset. Forecasts for book expenditure in 1960 are missing since the 1960-1961 survey does not record book expenditures with a sufficient level of detail.

of the baby-boom generation implies that the highest forecasted demand growth is for goods consumed later in life, such as cigars, cosmetics, and life insurance.

Table 2 also categorizes goods by their sensitivity to demographic shifts. For example, the demand for oil and utilities is unlikely to be affected by shifts in the relative cohort sizes, while the demand for bicycles and motorcycles depends substantially on the relative size of the cohorts age 15-20 and 20-30, respectively. We construct a measure of Demographic Industries using information available at time $t-1$ to identify the goods where demographic shifts are likely to have the most impact. In each year $t$ and industry $k$, we compute the standard deviation of the one-year consumption forecasts up to 15 years ahead given by $\left(\ln \hat{C}_{k, t+s+1 \mid t-1}-\right.$ $\left.\ln \hat{C}_{k, t+s \mid t-1}\right)$ for $s=0,1, \ldots, 15$. We define the set of Demographic Industries ${ }^{12}$ in each year $t$ as the 20 industries with the highest standard deviation of demand growth. In these industries, the forecasted aging of the population induces different demand shifts at different times in the future, enabling the estimation of investor horizon. For example, among the industries in Figure 3, books K-12 and books for college have

\footnotetext{
12 Ideally, we would like to select industries in which demographics better predicts contemporaneous profitability or revenue growth. Unfortunately, this avenue is not feasible for two reasons. First, demographics is a small predictor of revenue and profit, so one would need a long time series to identify the industries with the highest predictive power. For univariate series with 20-30 observations, the estimation would be poor. Second and relatedly, it would be impossible to do such a test in the early years of data without violating the requirement of using only backwardlooking information.
} 
Table 2-Summary Statistics for Predicted Demand Growth Rates

\begin{tabular}{|c|c|c|c|c|c|c|c|c|}
\hline \multirow[t]{3}{*}{ Expenditure category } & $\begin{array}{c}\text { No. } \\
\text { years }\end{array}$ & $\begin{array}{l}\text { Forecasted } \\
0-5 \text { growth }\end{array}$ & $\begin{array}{l}\text { Demogr. } \\
\text { industry }\end{array}$ & $\begin{array}{l}\text { Forecasted } \\
0-5 \text { growth }\end{array}$ & $\begin{array}{l}\text { Demogr. } \\
\text { industry }\end{array}$ & $\begin{array}{l}\text { Forecasted } \\
0-5 \text { growth }\end{array}$ & $\begin{array}{l}\text { Demogr. } \\
\text { industry }\end{array}$ & $\begin{array}{l}\% \text { Dem. } \\
\text { industry }\end{array}$ \\
\hline & & \multicolumn{2}{|c|}{1950} & \multicolumn{2}{|c|}{1975} & \multicolumn{2}{|c|}{2000} & \\
\hline & (1) & (2) & (3) & (4) & (5) & (6) & (7) & (8) \\
\hline Child care & 65 & 0.027 & Yes & 0.000 & Yes & 0.002 & Yes & $100 \%$ \\
\hline Children's books & 28 & - & - & - & - & 0.008 & Yes & $96 \%$ \\
\hline Children's clothing & 65 & 0.016 & Yes & 0.023 & Yes & 0.014 & Yes & $100 \%$ \\
\hline Toys & 65 & 0.027 & Yes & 0.004 & Yes & 0.008 & No & $89 \%$ \\
\hline Books: college text books & 65 & -0.008 & Yes & 0.027 & Yes & 0.016 & Yes & $100 \%$ \\
\hline Books: general & 65 & 0.006 & No & 0.021 & Yes & 0.010 & No & $88 \%$ \\
\hline Books: K-12 school books & 65 & 0.024 & Yes & -0.009 & Yes & 0.009 & Yes & $100 \%$ \\
\hline Movies & 65 & -0.001 & Yes & 0.023 & Yes & 0.012 & No & $51 \%$ \\
\hline Newspapers & 65 & 0.008 & No & 0.017 & No & 0.014 & No & $12 \%$ \\
\hline Magazines & 65 & 0.004 & No & 0.021 & Yes & 0.012 & No & $43 \%$ \\
\hline Cruises & 28 & - & - & - & - & 0.014 & No & $29 \%$ \\
\hline Dental equipment & 65 & 0.005 & No & 0.014 & No & 0.013 & No & $17 \%$ \\
\hline Drugs & 65 & 0.011 & No & 0.017 & No & 0.015 & Yes & $15 \%$ \\
\hline Health care (services) ${ }^{* *}$ & 65 & 0.011 & No & 0.017 & No & 0.014 & No & $15 \%$ \\
\hline Health insurance & 65 & 0.005 & No & 0.017 & No & 0.014 & Yes & $17 \%$ \\
\hline Medical equipment ${ }^{* *}$ & 65 & 0.011 & No & 0.017 & No & 0.014 & No & $15 \%$ \\
\hline Funeral homes and cemet. & 53 & 0.024 & Yes & - & No & 0.017 & Yes & $53 \%$ \\
\hline Nursing home care & 65 & 0.010 & No & 0.020 & Yes & 0.011 & Yes & $77 \%$ \\
\hline Construction equipment* & 65 & 0.006 & Yes & 0.020 & Yes & 0.012 & Yes & $100 \%$ \\
\hline Floors & 65 & 0.006 & No & 0.018 & No & 0.014 & Yes & $51 \%$ \\
\hline Furniture & 65 & 0.001 & Yes & 0.020 & Yes & 0.011 & No & $71 \%$ \\
\hline Home appliances, big & 65 & 0.004 & Yes & 0.017 & No & 0.012 & No & $37 \%$ \\
\hline Home appliances, small & 65 & 0.005 & No & 0.015 & No & 0.013 & No & $18 \%$ \\
\hline Housewares & 65 & 0.006 & No & 0.019 & Yes & 0.014 & Yes & $31 \%$ \\
\hline Linens & 65 & 0.008 & No & 0.017 & No & 0.013 & No & $31 \%$ \\
\hline Residential construction ${ }^{*}$ & 65 & 0.006 & Yes & 0.020 & Yes & 0.012 & Yes & $100 \%$ \\
\hline Residential development ${ }^{*}$ & 65 & 0.009 & No & 0.017 & No & 0.013 & No & $18 \%$ \\
\hline Residential mortgage & 65 & 0.015 & No & 0.016 & Yes & 0.007 & No & $52 \%$ \\
\hline Beer (and wine) & 65 & 0.003 & Yes & 0.021 & No & 0.011 & No & $74 \%$ \\
\hline Cigarettes & 65 & 0.001 & Yes & 0.018 & No & 0.013 & No & $42 \%$ \\
\hline Cigars and other tobacco & 65 & 0.010 & No & 0.014 & No & 0.016 & No & $2 \%$ \\
\hline Food & 65 & 0.009 & No & 0.015 & No & 0.013 & No & $0 \%$ \\
\hline Liquor & 28 & - & - & - & No & 0.014 & No & $11 \%$ \\
\hline Clothing (adults) & 65 & 0.003 & Yes & 0.020 & Yes & 0.013 & Yes & $48 \%$ \\
\hline Cosmetics & 65 & 0.002 & Yes & 0.022 & Yes & 0.015 & No & $34 \%$ \\
\hline Golf & 65 & 0.001 & Yes & 0.022 & Yes & 0.015 & Yes & $65 \%$ \\
\hline Jewelry & 65 & 0.003 & Yes & 0.019 & Yes & 0.013 & Yes & $34 \%$ \\
\hline Sporting equipment & 65 & 0.003 & Yes & 0.018 & No & 0.001 & No & $35 \%$ \\
\hline Life insurance & 65 & 0.008 & No & 0.014 & No & 0.015 & Yes & $37 \%$ \\
\hline Property insurance & 65 & 0.008 & No & 0.018 & No & 0.013 & No & $8 \%$ \\
\hline Airplanes & 28 & - & - & - & - & 0.014 & Yes & $11 \%$ \\
\hline Automobiles & 65 & 0.003 & Yes & 0.020 & Yes & 0.011 & No & $31 \%$ \\
\hline Bicycles & 65 & 0.019 & Yes & 0.003 & Yes & 0.004 & Yes & $86 \%$ \\
\hline Motorcycles & 28 & - & - & - & - & 0.011 & Yes & $75 \%$ \\
\hline Coal & 65 & 0.001 & No & 0.015 & No & 0.013 & No & $3 \%$ \\
\hline Oil & 65 & 0.006 & No & 0.016 & No & 0.013 & No & $0 \%$ \\
\hline Telephone & 65 & 0.008 & No & 0.018 & No & 0.013 & No & $9 \%$ \\
\hline Utilities & 65 & 0.008 & No & 0.015 & No & 0.014 & No & $6 \%$ \\
\hline Mean 0-5 cons. growth & & 0.008 & & 0.017 & & 0.012 & & \\
\hline Std. dev. $0-5$ cons. growth & & 0.007 & & 0.006 & & 0.003 & & \\
\hline
\end{tabular}

Notes: Complete list of expenditure categories, with number of years of availability of data (column 1) and average predicted five-year demand growth rate due to demographic changes in 1950 (column 2), in 1975 (column 4), and in 2000 (column 6). The last two rows present the mean and standard deviation of the five-year predicted consumption growth across all the goods in the relevant year. The table also indicates whether the industry belongs to the subsample of Demographic Industries in 1950 (column 3), in 1975 (column 5), and in 2000 (column 7). Each year the subset Demographic Industries includes the 20 industries with the highest standard deviation of forecasted annual consumption growth over the next 15 years. Column 8 presents percentage of the 65 years 1939-2003 in which the expenditure category belongs to the subsample of Demographic Industries, conditionally on being nonmissing. 
a higher standard deviation of forecasts, and are therefore more likely to be in the Demographic Industry subset. Column 3 shows that in 1950 the Demographic Industries are associated with high demand by children (child care, toys) and by young adults, such as housing. The classification is similar in the later years 1975 (column 5) and 2000 (column 7). Finally, column 8 summarizes the percentage of years in which an industry belongs to the subsample of Demographic Industries.

\section{Predictability Using Demographics}

In this section, we start by considering whether forecasted demand changes predict industry return on equity (the profitability measure) in panel regressions. Predictability of profitability is a necessary condition for the tests of abnormal return predictability. Next, we analyze return predictability using the same panel regression approach and also in a FamaMacBeth framework. Finally, we evaluate the performance of a trading strategy designed to exploit demographic information.

\section{A. ROE Predictability: Panel Regressions}

As a measure of profitability, we use a transformation of the accounting return on equity $(R O E)$. For each firm, the return on equity at time $t+1$ is defined as the ratio of earnings from the end of fiscal year $t$ through the end of fiscal year $t$ +1 (Compustat data item 172) to the book value of equity at the end of fiscal year $t$ (Compustat data item 60 or, if missing, Compustat data item 235). We construct the annual industry return on equity $R O E_{k, t+1}$ as the weighted average of $R O E$ for the companies in industry $k$. We use the book value for each company in year $t$ as the weights and drop companies with negative book values. The final measure is the log return on equity, roe $_{k, t+1}=\log \left(1+R O E_{k, t+1}\right)$. Columns 1 through 4 of Table 3 present summary statistics for the log annual return on equity (mean and standard deviation), the number of years for which data are available, and the average number of firms included in the industry over time.

Since some industries require a higher level of disaggregation than provided by the standard four-digit Standard Industrial Classification (SIC) codes, we create the industry classification ourselves whenever necessary. Using a companyby-company search within the relevant SIC codes, we partition the companies into the relevant groups. For example, the SIC code 5092 ("toys") includes both companies producing toys for children and companies manufacturing golf equipment, two goods clearly associated with consumption by different age groups. Appendix Table 1 displays the SIC codes for each industry. The SIC codes in parentheses are those that are shared by different industries, and therefore require a company-by-company search. For larger industries such as automobiles, oil, and coal, our classification yields portfolios that are similar to the industry portfolios generated by Fama and French (see Appendix B3 for details).

In Table 4, we test the predictability of the one-year industry log return on equity using the forecasted contemporaneous growth rate in consumption due to demographics (Table 2). Denote by $\hat{c}_{k, s \mid t}$ the natural log of the forecasted consumption of good $k$ in year $s$ forecasted as of year $t$. The following specification is motivated by equation (6):

$$
\operatorname{roe}_{k, t+1}=\lambda+\theta\left[\hat{c}_{k, t+2 \mid t-1}-\hat{c}_{k, t \mid t-1}\right] / 2+\varepsilon_{k, t} .
$$

The coefficient $\theta$ indicates the responsiveness of $\log$ return on equity in year $t+1$ to contemporaneous changes in demand due to forecasted demographic changes. Since the measure of cohort size for year $t+1$ refers to the July 1 value, approximately in the middle of the fiscal year, we use the average demand growth between July 1 of year $t$ and July 1 of year $t+2$ as a measure of contemporaneous demand change. We scale by two to annualize this measure. The forecast of consumption growth between years $t$ and $t+2$ uses only demographic and consumption information available up to year $t-1$. This lag ensures that all information should be public knowledge by year $t .^{13}$ We run specification (8) both with and without industry and year fixed effects.

In this panel setting, it is unlikely that the errors from the regression are uncorrelated across industries and over time because there are persistent shocks that affect multiple industries

\footnotetext{
${ }^{13}$ At present, the Bureau of the Census releases the demographic information for July 1 of year $t$ around December of the same year, that is, with less than a year lag.
} 
Table 3-Summary Statistics: Compustat Data, CRSP Data, and Concentration Ratios

\begin{tabular}{|c|c|c|c|c|c|c|c|c|c|}
\hline \multirow[b]{3}{*}{ Industry category } & \multicolumn{4}{|c|}{ Log yearly return on equity } & \multicolumn{4}{|c|}{$\begin{array}{c}\text { Value weighted annual } \\
\text { log stock return }\end{array}$} & \multirow{2}{*}{$\begin{array}{l}\text { Concen. } \\
\text { ratio } \\
(9)\end{array}$} \\
\hline & (1) & $(2)$ & (3) & (4) & (5) & (6) & $(7)$ & (8) & \\
\hline & Mean & Std. dev. & \# Years & \# Firms & Mean & Std. dev. & \# Years & \# Firms & $\begin{array}{l}\text { Largest } \\
4 \text { firms }\end{array}$ \\
\hline Child care & 0.104 & $(0.162)$ & 30 & 2.93 & 0.076 & $(0.431)$ & 32 & 3.38 & - \\
\hline Children's books & 0.089 & $(0.098)$ & 21 & 2.19 & 0.067 & $(0.288)$ & 22 & 2.36 & 0.202 \\
\hline Children's clothing & 0.162 & $(0.088)$ & 41 & 2.22 & 0.076 & $(0.342)$ & 42 & 2.98 & 0.170 \\
\hline Toys & 0.099 & $(0.109)$ & 41 & 9.73 & 0.075 & $(0.438)$ & 42 & 12.17 & 0.337 \\
\hline Books: college texts & 0.196 & $(0.059)$ & 25 & 2.08 & 0.146 & $(0.291)$ & 42 & 2.07 & 0.202 \\
\hline Books: general & 0.117 & $(0.073)$ & 42 & 7.24 & 0.115 & $(0.246)$ & 42 & 8.64 & 0.202 \\
\hline Books: $\mathrm{K}-12$ texts & 0.139 & $(0.044)$ & 37 & 2.27 & 0.116 & $(0.276)$ & 39 & 2.85 & 0.202 \\
\hline Movies & 0.070 & $(0.117)$ & 53 & 18.72 & 0.114 & $(0.304)$ & 65 & 22.71 & - \\
\hline Newspapers & 0.176 & $(0.080)$ & 52 & 10.77 & 0.137 & $(0.257)$ & 65 & 10.48 & 0.170 \\
\hline Magazines & 0.099 & $(0.067)$ & 42 & 6.33 & 0.127 & $(0.291)$ & 42 & 7.98 & 0.260 \\
\hline Cruises & 0.233 & $(0.183)$ & 18 & 3.61 & 0.176 & $(0.309)$ & 18 & 3.72 & - \\
\hline Dental equipment & 0.070 & $(0.270)$ & 43 & 3.12 & 0.064 & $(0.356)$ & 65 & 3.26 & 0.350 \\
\hline Drugs & 0.183 & $(0.021)$ & 53 & 91.51 & 0.127 & $(0.190)$ & 65 & 98.31 & 0.282 \\
\hline Health care (services) & 0.113 & $(0.049)$ & 35 & 46.26 & 0.115 & $(0.337)$ & 36 & 56.28 & - \\
\hline Health insurance & 0.101 & $(0.043)$ & 32 & 12.97 & 0.096 & $(0.220)$ & 42 & 14.29 & - \\
\hline Medical equipment & 0.141 & $(0.029)$ & 53 & 60.32 & 0.149 & $(0.225)$ & 65 & 62.51 & 0.374 \\
\hline Funeral homes, cemet. & 0.060 & $(0.130)$ & 29 & 2.97 & 0.118 & $(0.511)$ & 30 & 2.90 & 0.250 \\
\hline Nursing home care & 0.076 & $(0.092)$ & 35 & 14.63 & 0.046 & $(0.433)$ & 35 & 17.60 & - \\
\hline Construction equip. & 0.123 & $(0.097)$ & 42 & 21.81 & 0.119 & $(0.242)$ & 42 & 24.64 & 0.430 \\
\hline Floors & 0.083 & $(0.039)$ & 47 & 5.38 & 0.081 & $(0.356)$ & 65 & 6.26 & - \\
\hline Furniture & 0.010 & $(0.029)$ & 53 & 15.92 & 0.093 & $(0.260)$ & 65 & 15.72 & 0.166 \\
\hline Home appliances big & 0.149 & $(0.071)$ & 53 & 20.60 & 0.115 & $(0.305)$ & 65 & 21.20 & 0.632 \\
\hline Home appliances small & 0.153 & $(0.045)$ & 53 & 5.08 & 0.136 & $(0.253)$ & 55 & 5.49 & 0.430 \\
\hline Housewares & 0.082 & $(0.144)$ & 40 & 3.05 & 0.091 & $(0.313)$ & 42 & 3.29 & 0.575 \\
\hline Linens & 0.100 & $(0.127)$ & 39 & 4.03 & 0.101 & $(0.544)$ & 39 & 4.62 & 0.263 \\
\hline Residential const. & 0.092 & $(0.082)$ & 41 & 12.37 & 0.075 & $(0.460)$ & 42 & 13.07 & - \\
\hline Residential develop. & 0.068 & $(0.049)$ & 42 & 42.60 & 0.071 & $(0.310)$ & 42 & 53.36 & - \\
\hline Residential mortgage & 0.109 & $(0.375)$ & 38 & 12.34 & 0.087 & $(0.385)$ & 42 & 14.26 & - \\
\hline Beer (and wine) & 0.126 & $(0.045)$ & 53 & 7.43 & 0.111 & $(0.227)$ & 65 & 8.88 & 0.519 \\
\hline Cigarettes & 0.168 & $(0.044)$ & 53 & 4.06 & 0.128 & $(0.216)$ & 65 & 5.11 & 0.840 \\
\hline Cigars, other tobacco & 0.231 & $(0.254)$ & 52 & 4.62 & 0.127 & $(0.214)$ & 65 & 5.97 & 0.656 \\
\hline Food & 0.134 & $(0.024)$ & 53 & 175.92 & 0.114 & $(0.163)$ & 65 & 183.48 & 0.360 \\
\hline Liquor & 0.133 & $(0.121)$ & 28 & 4.32 & 0.145 & $(0.147)$ & 28 & 5.29 & 0.470 \\
\hline Clothing (adults) & 0.130 & $(0.033)$ & 53 & 45.75 & 0.103 & $(0.263)$ & 65 & 48.92 & 0.158 \\
\hline Cosmetics & 0.225 & $(0.125)$ & 48 & 9.96 & 0.110 & $(0.299)$ & 65 & 9.48 & 0.380 \\
\hline Golf & 0.043 & $(0.130)$ & 32 & 4.16 & 0.030 & $(0.406)$ & 32 & 5.25 & - \\
\hline Jewelry & 0.087 & $(0.047)$ & 42 & 9.67 & 0.116 & $(0.349)$ & 42 & 11.40 & 0.203 \\
\hline Sporting equipment & 0.125 & $(0.134)$ & 53 & 6.98 & 0.083 & $(0.383)$ & 65 & 7.05 & 0.280 \\
\hline Life insurance & 0.099 & $(0.079)$ & 41 & 13.29 & 0.120 & $(0.273)$ & 41 & 36.24 & - \\
\hline Property insurance & 0.111 & $(0.052)$ & 32 & 29.25 & 0.010 & $(0.192)$ & 65 & 23.82 & - \\
\hline Airplanes & 0.096 & $(0.068)$ & 28 & 43.18 & 0.124 & $(0.212)$ & 28 & 48.64 & 0.621 \\
\hline Automobiles & 0.121 & $(0.103)$ & 53 & 59.15 & 0.108 & $(0.235)$ & 65 & 66.66 & 0.807 \\
\hline Bicycles & 0.069 & $(0.121)$ & 37 & 1.41 & 0.027 & $(0.421)$ & 37 & 1.49 & 0.650 \\
\hline Motorcycles & 0.291 & $(0.204)$ & 20 & 1.30 & 0.169 & $(0.347)$ & 25 & 1.28 & 0.650 \\
\hline Coal & 0.069 & $(0.104)$ & 47 & 7.00 & 0.112 & $(0.248)$ & 65 & 9.95 & - \\
\hline Oil & 0.111 & $(0.038)$ & 53 & 164.72 & 0.117 & $(0.175)$ & 65 & 173.51 & - \\
\hline Telephone & 0.078 & $(0.049)$ & 53 & 20.08 & 0.086 & $(0.240)$ & 65 & 25.97 & - \\
\hline Electricity & 0.101 & $(0.034)$ & 45 & 165.29 & 0.097 & $(0.171)$ & 65 & 147.40 & - \\
\hline
\end{tabular}

Notes: The measure of $R O E$ in year $t+1$ is the ratio of earnings in year $t+1$ to the book value of equity in year $t$. The industry measure of $R O E$ is the average of $R O E$ weighted by the book value of equity in year $t$. Column 1 displays the log of 1 plus the industry $R O E$. Column 2 reports the within-industry standard deviation. Also featured are the number of years for which the data are available (column 3) and the average number of firms in the industry (column 4). The measure of annual industry stock return in year $t+1$ is the $\log$ of 1 plus the value-weighted average stock return for all companies belonging to the industry between December 31 in year $t$ and December 31 in year $t+1$ (column 5). The average is value-weighted by the market capitalization at the end of year $t$. Columns 6 through 8 are parallel to columns 2 through 4 . The concentration ratio measure (column 9) is the ratio of revenue produced by the largest four companies to the total industry revenue from the Census of Manufacturers in 1972. The measure is the average across all the four-digit SIC codes that define the industry, weighted by the revenue in each the SIC code group. The measure is missing for industries with no SIC codes within the manufacturing range (2000-3999). If these data are missing for an industry in 1972, then the measure, if available, is collected from Census of Manufacturers in 1970. 
at the same time. We allow for heteroskedasticity and arbitrary contemporaneous correlation across industries by calculating standard errors clustered by year. In addition, we correct these standard errors to account for autocorrelation in the error structure.

More formally, let $\boldsymbol{X}$ be the matrix of regressors, $\boldsymbol{\theta}$ the vector of parameters, and $\boldsymbol{\varepsilon}$ the vector of errors. The panel has $T$ periods and $K$ industries. Under the appropriate regularity conditions, $\sqrt{1 / T}(\hat{\boldsymbol{\theta}}-\boldsymbol{\theta})$ is asymptotically distributed $N\left(\mathbf{0},\left(\boldsymbol{X}^{\prime} \boldsymbol{X}\right)^{-1} \boldsymbol{S}\left(\boldsymbol{X}^{\prime} \boldsymbol{X}\right)^{-1}\right)$, where $\boldsymbol{S}=\boldsymbol{\Gamma}_{0}+\sum_{q=1}^{\infty}\left(\boldsymbol{\Gamma}_{q}\right.$ $\left.+\boldsymbol{\Gamma}_{q}^{\prime}\right)$ and $\boldsymbol{\Gamma}_{q}=\mathrm{E}\left[\left(\sum_{k=1}^{K} \boldsymbol{X}_{k t} \boldsymbol{\varepsilon}_{k t}\right)^{\prime}\left(\sum_{k=1}^{K} \boldsymbol{X}_{k t-q} \boldsymbol{\varepsilon}_{k t-q}\right)\right]$. The matrix $\boldsymbol{\Gamma}_{0}$ captures the contemporaneous covariance, while the matrix $\boldsymbol{\Gamma}_{q}$ captures the covariance structure between observations that are $q$ periods apart. While we do not make any assumptions about contemporaneous covariation, we assume that $\boldsymbol{X}_{k t}^{\prime} \boldsymbol{\varepsilon}_{k t}$ follows an autoregressive process given by $\boldsymbol{X}_{k t}^{\prime} \boldsymbol{\varepsilon}_{k t}=$ $\rho \boldsymbol{X}_{k t-1}^{\prime} \boldsymbol{\varepsilon}_{k t-1}+\boldsymbol{\eta}_{k t}^{\prime}$, where $\rho<1$ is a scalar and $E\left[\left(\sum_{k=1}^{K} \boldsymbol{X}_{k t-q} \boldsymbol{\varepsilon}_{k t-q}\right)^{\prime}\left(\sum_{k=1}^{K} \boldsymbol{\eta}_{k t}\right)\right]=\mathbf{0}$ for any $q>0$.

These assumptions imply $\boldsymbol{\Gamma}_{q}=\rho^{q} \boldsymbol{\Gamma}_{0}$ and therefore, $\boldsymbol{S}=[(1+\rho) /(1-\rho)] \boldsymbol{\Gamma}_{0}$ (see derivation in Appendix C). The higher the autocorrelation coefficient $\rho$, the larger are the terms in the matrix $S$. Since $\Gamma_{0}$ and $\rho$ are unknown, we estimate $\boldsymbol{\Gamma}_{0}$ with ${ }^{1 / T} \sum_{t=1}^{T} \boldsymbol{X}_{t}^{\prime} \hat{\boldsymbol{\varepsilon}}_{t} \hat{\boldsymbol{\varepsilon}}_{t}^{\prime} \boldsymbol{X}_{t}$, where $\boldsymbol{X}_{t}$ is the matrix of regressors and $\hat{\boldsymbol{\varepsilon}}_{t}$ is the vector of estimated residuals for each cross section. We estimate $\rho$ from the pooled regression for each element of $\boldsymbol{X}_{k t}^{\prime} \hat{\boldsymbol{\varepsilon}}_{k t}$ on the respective element of $\boldsymbol{X}_{k t-1}^{\prime} \hat{\boldsymbol{\varepsilon}}_{k t-1}$.

We use the set of Demographic Industries for the years 1974-2003 as the baseline sample for the paper. As discussed above, the Demographic Industries are more likely to be affected by demographic demand shifts. As for the time period, data accuracy is higher over the more recent time period. Before 1974, and particularly before 1963 , very few of the industries that we associate with significant demographic patterns exist (Table 3, columns 3 and 7), and the industries that are available have fewer stocks in them. (In 1963 and 1973, the Center for Research in Security Prices (CRSP) substantially expanded its coverage.) In addition, the consumption data are available at a finer level of disaggregation in the 1972-1973 and 1983-1984 expenditure surveys.
In the specification for the baseline sample without industry or year fixed effects (column 1 of Table 4), the impact of demographics on $R O E$ is identified by both between- and withinindustry variation in demand growth. The estimated coefficient, $\hat{\theta}=2.71$, is significant and economically large. A 1 percent increase in yearly consumption growth due to demographics increases the log return on equity from an average of 11.1 percent to an average of 13.8 percent, a 24 percent increase. ${ }^{14}$ (A 1 percent increase in consumption growth corresponds approximately to a 1.6 standard deviation movement. ${ }^{15}$ The $R^{2}$ of the regression is low due to the modest role of demographic changes relative to other determinants of profitability. In this and subsequent specifications, controlling for autocorrelation is important. The estimated $\hat{\rho}$ in column 1 is 0.43 , resulting in a proportional correction for the standard errors of $\sqrt{(1+\hat{\rho}) /(1-\hat{\rho})}=1.58$. The correction is smaller in the specifications with industry and year fixed effects. In column 2, we introduce industry fixed effects. In this case, the identification depends only on within-industry variation in demand growth. The estimate for $\theta$ is significant and larger than in column 1, with $\hat{\theta}=3.42$. In column 3 , we introduce year fixed effects as well. In this specification, the identification depends on within-industry variation in demand growth after controlling for common time-series patterns. The estimated coefficient, $\hat{\theta}=1.83$, is smaller, but is also statistically significantly different from zero.

In columns 4 through 9, we examine a longer time period (1939-2003) and a larger set of industries. For the longer time period 19392003 (columns 4 through 6), the estimates of $\theta$ are generally lower than the baseline results, but still economically large and significant (only marginally significant in column 4). For the larger sample with all 48 industries (columns 7 through 9), the estimates for $\theta$ are similar to the corresponding ones for the subset of Demographic Industries. The standard errors

\footnotetext{
${ }^{14}$ The point estimate $\hat{\theta}=2.71$ is higher than the maximum $\theta$ implied by the model, since $\theta_{S R}=(1+R) /(2+R)$ $<1$. However, the predictions of the model regarding point estimates should be taken with caution, since the two-period model is stylized. In addition, the confidence interval for $\hat{\theta}$ includes the entire range $[0.5,1]$ predicted by the model.

15 The mean two-year forecasted consumption growth measure is 0.0146 , with standard deviation 0.0063 .
} 
Table 4-Predictability of Return on Equity Using Demographic Changes

\section{Sample}

(1)

$(2)$

Demographic industries

Constant
Forecasted annualized
demand growth
between $t$ and $t+2$

Industry fixed effects

Year fixed effects

Sample: 1974 to 2003

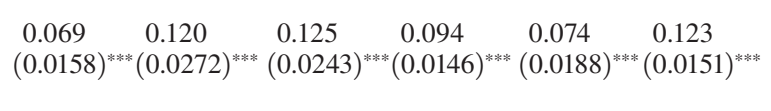

$\begin{array}{llllll}2.710 & 3.417 & 1.830 & 1.663 & 2.412 & 2.469 \\ (1.1128)^{* * *}(1.0174)^{* * *} & (0.9187)^{* *}(0.9031)^{*} & (0.9159)^{* * * *}(0.9987)^{* *}\end{array}$

$\mathrm{X}$

$\mathrm{X}$

$\mathrm{X}$

$\mathrm{X}$

$\mathrm{X}$

$\begin{array}{lll}2.624 & 3.887 & 2.637 \\ (1.2165)^{* * *} & (1.2223)^{* * * *}(1.2699)^{* *}\end{array}$

$\begin{array}{cc}0.079 & 0.004 \\ (0.0187)^{* * * *}(0.045)\end{array}$

0.003

(0.047)

$t+1$

All industries

(8)

(9)

X $\quad X \quad$ X

$\mathrm{X}$

$\mathrm{X}$

$\mathrm{X}$

$\mathrm{X}$

Sample: 1939 to 2003

\begin{tabular}{llllllllll}
$R^{2}$ & 0.020 & 0.273 & 0.329 & 0.008 & 0.186 & 0.242 & 0.001 & 0.228 & 0.262 \\
$N$ & $N=564$ & $N=564$ & $N=564$ & $N=860$ & $N=860$ & $N=860$ & $N=1382$ & $N=1382 N=1382$ \\
\hline
\end{tabular}

Notes: Columns 1 through 9 report the coefficients of OLS regressions of annual log return on equity at $t+1$ on the forecasted annualized demand growth due to demographics between years $t$ and $t+2$. The forecast is made using information available as of year $t-1$. The coefficients on the forecasted annual demand growth are normalized by the number of years of the forecast (two for this coefficient). The coefficient indicates the average increase in log industry return on equity (an accounting measure of profitability) due to an annualized 1 percentage point increase in consumption due to demographics. Each year the subset of Demographic Industries includes the 20 industries with the highest standard deviation of forecasted annual consumption growth over the next 15 years. Robust standard errors are clustered by year and then scaled by a function of the autocorrelation coefficient estimated from the sample orthogonality conditions. A thorough description of the standard errors is available in the text.

**** Significant at, or below, 1 percent.

** Significant at, or below, 5 percent.

* Significant at, or below, 10 percent.

for the estimates using all of the industries are larger than those for the estimates using only the Demographic Industries subsample. Given a threefold increase in sample size, the larger standard errors suggest a lower signal-to-noise ratio for the nondemographic industries. Indeed, when we estimate specification (8) exclusively on the complementary set (non-Demographic Industries), the point estimates are similar, but the standard errors are four times as large, despite a greater number of observations.

Forecasted demand changes due to demographics have a statistically and economically significant effect on industry-level profitability. It appears that entry and exit by firms into industries does not fully undo the impact of forecastable demand changes on profitability.

Industry Concentration.-The impact of a demand change on profitability should depend on the market structure. At one extreme, in a perfectly competitive industry with no barriers to entry, the consumers capture all the surplus arising from a positive demand shift. In this scenario, demographic changes do not affect abnormal profits. At the other extreme, a monopolist in an industry with high barriers to entry generates additional profits from a positive demand change. We address this issue by estimating how the impact of demand changes on profitability varies with measures of barriers to entry.

As a proxy for barriers to entry and/or market power, we use the concentration ratio C-4 from the Census of Manufacturers. This ratio is the fraction of industry revenue produced by the four largest companies, including companies that are not publicly traded. It is available for industrial sectors with four-digit SIC codes between 2000 and 3999 . We compute the industry measure as a weighted average of the C-4 ratio for the SIC 
codes included in our industry definition in the range 2000-3999, using revenue for each SIC code as weights. We use the concentration ratios from 1972 (or 1970 if the 1972 data are missing) to guarantee that the information about industrial organization is collected before the beginning of the benchmark sample in 1974. Unfortunately, concentration ratios are not available for nonmanufacturing industries, such as insurance and utilities, that do not have a SIC code within the appropriate range. Among the 31 industries with concentration data (column 9 in Table 3), the median C-4 ratio is 0.35 .

In Table 5, we present the results on industry concentration. For the subsample of industries with above-median concentration (columns 1 through 3 of Table 5), the estimates for $\theta$, capturing the impact of demographics on profitability, are higher than the benchmark estimates (Table 4). The coefficient estimate $\hat{\theta}$ is not significant in the first two specifications (columns 1 and 2), but is significant with industry and year fixed effects (column 3 ). While the estimate $\hat{\theta}=$ 8.81 is abnormally large, we cannot reject the hypothesis that $\theta$ is in the range of the estimates from the benchmark specifications in Table 4 . For the sample of unconcentrated industries (columns 4 through 6), the estimate of $\theta$ is smaller and not significantly different from zero. We interpret these findings as suggestive evidence that demand changes due to demographics alter profits more substantially in the presence of barriers to entry.

Age Groups.-Our results suggest that demographic shifts affect industry profitability. To try to estimate which groups of industries identify the results, we separate industries in three broad groups, Young, Adult, and Elderly. The Young group includes all the industries under the Children grouping (Appendix Table 1), books for college, books for K-12, and bicycles. The Elderly group includes the Health grouping and the Senior grouping. The Adult group includes the other 33 industries. When we analyze the $R O E$ predictability result by age group (not shown), we find evidence of predictability for the Young and Adult age group. The estimates for the Elderly age group, while large, are imprecisely estimated. The growth in the elderly population does not change much over time (Figure 1D), limiting the variation in the demand shifts, and thus reducing the precision of the estimates.

\section{B. Return Predictability: Panel Regressions}

Using the same panel framework, we examine the relationship between forecasted demand growth and industry-level stock returns. We aggregate firm-level stock returns from CRSP to form value-weighted industry-level returns. The aggregation procedure is identical to the methodology used for the profitability measure. The sample of returns is larger than the sample of accounting profitability because returns data are available for a longer time period and for more companies. The market capitalization is generally smaller for Demographic Industries than for non-Demographic Industries. In 1975, for example, the average market capitalization for the Demographic Industries is $\$ 2.4$ billion and for non-Demographic Industries is $\$ 13.8$ billion.

We choose specifications motivated by expression (7) in Section I and investigate when stock prices incorporate the forecastable consumption changes generated by demographic variables. In the baseline specification, we regress annual returns on the forecasted growth rate of demand due to demographics from $t$ to $t+5$ (the short term) and $t+5$ to $t+10$ (the long term). We use beta-adjusted returns to remove market-wide shocks, including the potential impact of demographic changes on aggregate returns. ${ }^{16}$. Define $r_{k, u, t}$ to be the natural log of the stock return for good $k$ between the end of year $t$ and the end of year $u$. The log of the market return and of the risk-free rate over the same horizon are $r_{m, u, t}$ and $r_{f, u, t}$. Further, let $\hat{\beta}_{k, t}$ be the coefficient of a regression of monthly industry excess returns on market excess returns over the 48 months previous to year $t .{ }^{17}$ We define the abnormal log return $a r_{k, u, t}=\left(r_{k, u, t}-r_{f, u, t}\right)-\hat{\beta}_{k, t}\left(r_{m, u, t}-r_{f, u, t}\right)$. The specification of the regression is

$$
\begin{aligned}
\operatorname{ar}_{k, t+1, t}= & \gamma+\delta_{0}\left[\hat{c}_{k, t+5 \mid t-1}-\hat{c}_{k, t \mid t-1}\right] / 5 \\
& +\delta_{1}\left[\hat{c}_{k, t+10 \mid t-1}-\hat{c}_{k, t+5 \mid t-1}\right] / 5+\varepsilon_{k, t}
\end{aligned}
$$

\footnotetext{
16 The results are the same if we use log net-of-market returns instead of abnormal log returns, or if we use abnormal returns in levels instead of logs.

${ }^{17} \mathrm{We}$ require a minimum of 30 observations for the estimation of $\beta$.
} 
TABle 5-Predictability of Return on Equity ANd Industry ConCEntration

\begin{tabular}{|c|c|c|c|c|c|c|}
\hline \multirow{3}{*}{ Sample } & \multicolumn{6}{|c|}{ Dependent variable: Annual log return on equity $(R O E)$ at $t+1$} \\
\hline & & $4>$ median & & & $4 \leq$ median & \\
\hline & (1) & $(2)$ & (3) & (4) & $(5)$ & (6) \\
\hline Constant & $\begin{array}{c}0.090 \\
(0.063)\end{array}$ & $\begin{array}{l}0.244 \\
(0.0787)^{* * * *}\end{array}$ & $\begin{array}{c}0.136 \\
(0.105)\end{array}$ & $\begin{array}{l}0.098 \\
(0.0178)^{* * *}\end{array}$ & $\begin{array}{l}0.073 \\
(0.0282)^{* *}\end{array}$ & $\begin{array}{l}0.069 \\
(0.0299)^{* * *}\end{array}$ \\
\hline $\begin{array}{l}\text { Forecasted annualized } \\
\text { demand growth } \\
\text { between } t \text { and } t+2\end{array}$ & $\begin{array}{c}4.228 \\
(3.972)\end{array}$ & $\begin{array}{c}4.864 \\
(3.573)\end{array}$ & $\begin{array}{l}8.806 \\
(4.2331)^{* * *}\end{array}$ & $\begin{array}{c}0.842 \\
(1.181)\end{array}$ & $\begin{array}{c}1.137 \\
(1.337)\end{array}$ & $\begin{array}{c}0.344 \\
(1.254)\end{array}$ \\
\hline Industry fixed effects & & $\mathrm{X}$ & $\mathrm{X}$ & & $\mathrm{X}$ & $\mathrm{X}$ \\
\hline Year fixed effects & & & $\mathrm{X}$ & & & $\mathrm{X}$ \\
\hline Sample: 1974 to 2003 & $\mathrm{X}$ & $\mathrm{X}$ & $\mathrm{X}$ & $\mathrm{X}$ & $\mathrm{X}$ & $\mathrm{X}$ \\
\hline$R^{2}$ & 0.013 & 0.266 & 0.366 & 0.002 & 0.110 & 0.209 \\
\hline$N$ & $N=435$ & $N=435$ & $N=435$ & $N=449$ & $N=449$ & $N=449$ \\
\hline
\end{tabular}

Notes: Columns 1 through 6 report the coefficients of OLS regressions of log yearly return on equity at $t+1$ on the forecasted annualized demand growth due to demographics between year $t$ and year $t+2$ from 1974 until 2003 . The forecast is made using information available as of year $t-1$. The coefficients on the forecasted annual demand growth are normalized by the number of years of the forecast, two. The coefficient indicates the typical increase in log industry return on equity (an accounting measure of profitability) due to an annualized 1 percentage point increase in consumption due to demographics. The concentration ratio measure $\mathrm{C}-4$ is the ratio of revenue for the largest four firms to total industry revenue, from the Census of Manufacturers conducted in 1972 (or 1970 if the 1972 measure is missing). Columns 1 through 3 report the results for all industries with a concentration ratio higher than the median of 0.35 . Columns 4 through 6 report the results for all industries with a concentration ratio lower than or equal to the median. Standard errors are clustered by year and then scaled by a function of the autocorrelation coefficient estimated from the sample orthogonality conditions. A more thorough description of the concentration ratio measure and the standard errors is available in the text.

$* * *$ Significant at, or below, 1 percent.
** Significant at, or below, 5 percent.
* Significant at, or below, 10 percent.

Since the consumption growth variables are scaled by five, the coefficients $\delta_{0}$ and $\delta_{1}$ represent the average increase in abnormal yearly returns for 1 percentage point of additional annualized growth in demographics. Once again, the forecasts of consumption as of time $t$ use only information available in period $t-1$.

The model in Section I suggests that, if the forecast horizon $h$ is shorter than five years, the coefficient $\delta_{0}$ should be positive and $\delta_{1}$ should be zero. If the forecast horizon is between five and ten years, the coefficient $\delta_{0}$ should be zero or negative and the coefficient $\delta_{1}$ should be positive. Finally, if the investors have a horizon greater than ten years (including rational investors with $h \rightarrow \infty$ ), both coefficients should be zero. A significantly positive coefficient indicates that stock prices adjust as the demographic information enters the forecast horizon.
Columns 1 through 3 of Table 6 present the estimates of (9) for the sample of Demographic Industries during the years 1974-2003. In the specification without year or industry indicators (column 1), the coefficient on short-term demographics, $\hat{\delta}_{0}=-1.52$, is not significantly different from zero, while the coefficient on long-term demographics, $\hat{\delta}_{1}=8.92$, is significantly larger than zero. A 1 percentage point annualized increase in demand from year 5 to year 10 increases the average abnormal yearly stock return by 8.92 percentage points. (A 1 percentage point increase in demand growth corresponds approximately to a 1.8 standard deviation movement. ${ }^{18}$ In this and the subsequent speci-

\footnotetext{
${ }^{18}$ For this sample, the mean forecasted demand growth five to ten years ahead is 0.0118 , with standard deviation 0.0058 .
} 
Table 6-Predictability of Stock Returns Using Demographic Changes

Dependent variable: Annual beta-adjusted log industry stock return at $t+1$

Sample Demographic industries

(1)

(2)

(3)

(4)

(5)

(6)

(7)

All industries

Constant
Forecasted annualized
demand growth
between $t$ and $t+5$
Forecasted annualized
demand growth
between $t+5$
and $t+10$

Industry fixed effects $\begin{array}{cc}-0.090 & 0.122 \\ (0.057) & (0.100)\end{array}$

$\begin{array}{ccc}0.377 & -0.050 & -0.038 \\ (0.0751)^{* * * *}(0.033) & (0.044)\end{array}$

0.073

$\begin{array}{cc}-0.081 & -0.069 \\ (0.050) & (0.063)\end{array}$

(8)

(9)

$\begin{array}{ccccccccc}-1.522 & -1.983 & -2.911 & -2.063 & -2.521 & -3.173 & -2.364 & -2.186 & -2.482 \\ (4.329) & (4.128) & (3.520) & (2.722) & (3.014) & (2.886) & (4.248) & (4.721) & (3.246) \\ & & & & & & & & \\ 8.917 & 11.297 & 6.918 & 5.621 & 6.229 & 5.000 & 8.944 & 11.522 & 6.729 \\ (4.0339)^{* *} & (3.8097)^{* * * *} & (3.6965)^{* *} & (3.3082)^{*} & (3.3635)^{*} & (2.8069)^{*} & (3.4437)^{* * *} & (3.9984)^{* * * *} & (3.8688)^{*}\end{array}$

0.113

$(0.0661)^{*}$

Indusy fixed effects

X

X

$\mathrm{X}$

$\mathrm{X}$

X

$\mathrm{X}$

Year fixed effects

X

$\mathrm{X}$

X

Sample: 1974 to 2003

X

X

$\mathrm{X}$

X

$\mathrm{X}$

$\mathrm{X}$

Sample: 1939 to 2003

\begin{tabular}{ccccccccc} 
& & \multicolumn{1}{c}{$\mathrm{X}$} & $\mathrm{X}$ & $\mathrm{X}$ & & & \\
0.022 & 0.103 & 0.314 & 0.009 & 0.063 & 0.311 & 0.015 & 0.052 & 0.193 \\
$N=569$ & $N=569$ & $N=569$ & $N=920$ & $N=920$ & $N=920$ & $N=1387$ & $N=1387$ & $N=1387$ \\
\hline
\end{tabular}

$R^{2}$

$N=569 \quad N=569$

Notes: Columns 1 through 9 report the coefficients of OLS regressions of log yearly beta-adjusted industry stock returns at $t+1$ on the forecasted annualized demand growth due to demographics between $t$ and $t+5$ and between $t+5$ and $t+10$. The forecasts are made using information available as of year $t-1$. The industry betas for year $t$ are obtained by regressing monthly industry excess log returns on excess log market returns for the 48 months previous to year $t$. The coefficients on the forecasted annual demand growth are normalized by the number of years of the forecast (five for both coefficients). The coefficient indicates the average increase in log industry abnormal stock return due to an annualized 1 percentage point increase in forecasted consumption due to demographics. Each year the subset of Demographic Industries includes the 20 industries with the highest standard deviation of forecasted annual consumption growth over the next 15 years. Robust standard errors are clustered by year and then scaled by a function of the autocorrelation coefficient estimated from the sample orthogonality conditions. A thorough description of the standard errors is available in the text.

*** Significant at, or below, 1 percent.

** Significant at, or below, 5 percent.

* Significant at, or below, 10 percent.

fications, $\hat{\rho}$ is approximately 0.1 , resulting in a proportional correction for the standard errors of $\sqrt{(1+\hat{\rho}) /(1-\hat{\rho})}=1.11$. The coefficients are somewhat larger when industry fixed effects (column 2) are introduced. The introduction of year fixed effects (column 3 ) lowers the estimate of $\delta_{1}$ to a still large and marginally significant estimate of 6.92. This difference suggests that the year fixed effects absorb some of the common time-series variation in demographics.

In the longer sample (columns 4 through 6), the estimated coefficient on long-term demographics is about half as large and marginally significant in all three specifications, while the coefficient on short-term demographics is still negative and insignificant. In the early years, most of the industries with significant age patterns are missing. The estimates for the sample of all industries (columns 7 through 9) are close to the estimates for the Demographic Industries, with a similar pattern of statistical significance.

Industry Concentration.-As we discussed above, testing attention using stock market reaction to demand changes is more meaningful for industries with substantial barriers to entry. In columns $1-4$ of Table 7 we replicate specification (9) separately for industries with C-4 concentration ratio (measured in 1972) above and below the median of 0.35 . For the industries 
with above-median concentration (column 1) the estimated coefficient $\hat{\delta}_{1}$ on demand growth between $t+5$ and $t+10$ is similar to the estimated coefficient $\hat{\delta}_{1}$ for the sample of all industries and marginally significant; the coefficient $\hat{\delta}_{1}$ remains large but is not significant with industry fixed effects (column 2) and with industry and year fixed effects (column 3). For the industries with below-median concentration (columns 4 through 6), the point estimates are smaller, except in the specification with industry fixed effects (column 5). To summarize, there is suggestive evidence of stronger return predictability in industries with higher concentration, but not significantly so.

Age Groups.-We also estimate specification (9) separately by demographic subgroup. We find significant predictability for the Young and the Adult group of industries, except with industry and year fixed effects (results not shown). There is no evidence of predictability in the Elderly group of industries.

Industry Turnover and Private Firms.-We have explored the extent to which the results vary with the turnover of firms in an industry, and with the share of companies in an industry that are publicly traded (results not shown). We find some evidence that industries with higher turnover have a higher return predictability, suggesting that limits to arbitrage may enhance predictability. Industries with a larger share of public companies relative to the private companies also display higher predictability, suggesting that private companies may sometimes absorb the impact of demand shifts. Both of these results, however, are imprecisely estimated.

Horizon of Return Predictability.-We consider a specification of return predictability that is more closely linked with the model of shortsighted investors in Section I. We estimate the regression

$$
a r_{k, t+1, t}=\lambda+\delta_{H}\left(\hat{c}_{k, t+h+1 \mid t-1}-\hat{c}_{k, t+h \mid t-1}\right)+\varepsilon_{k, t}
$$

for the sample of Demographic Industries ${ }^{19}$ over the years 1974-2003, for investor horizon $h$

\footnotetext{
${ }^{19}$ The results are similar if all industries are included in the analysis.
}

between 0 and 15 years. The coefficient $\delta_{H}$ measures the extent to which consumption growth $h$ years ahead forecasts stock returns in year $t+1$ (Figure 4). The coefficient $\delta_{H}$ on contemporaneous demand growth $(h=0$ or $h=1)$ is small and insignificant. The coefficient increases with the horizon $h$ and becomes significantly positive for $h=4$, reaching the peak value of 7.98 at the horizon of seven years. The coefficient then decreases for larger $h$ and becomes insignificant for $h=9$. Abnormal return predictability is significant for forecasted demand growth occurring four to eight years in the future.

The tent-shaped pattern of Figure 4 is consistent with the predictions of the model in Section I for a foresight horizon of four to eight years. The information that is closer than four years into the future does not predict stock returns because it is already incorporated into stock prices. The information that is further than eight years into the future does not predict stock returns either, but for a different reason: that information is still not incorporated in the investor information set at the end of year $t$. The information that is just at the edge of the foresight horizon, instead, is incorporated by investors during year $t$, and therefore predicts returns.

\section{Return Predictability: Fama-MacBeth Regressions}

In Table 8, we present the results of FamaMacBeth regressions as an alternative estimation approach that controls for time-series patterns. We estimate separate cross-sectional regressions of (9) for each year $t$ from 1974 until 2003, and then compute the time-series average of the estimated coefficients. Since the regression is estimated separately for each year, year effects that may be correlated with returns and with demographics do not contribute to the identification of the coefficients $\delta_{0}$ and $\delta_{1}$. The standard errors are based on the time-series variation of the OLS coefficients using a Newey-West estimator with three lags.

We first estimate the regressions for the sample of Demographic Industries, with betaadjusted industry returns as the dependent variable. ${ }^{20}$ The short-run forecasted demand growth

\footnotetext{
${ }^{20}$ For consistency with the standard approach in the cross-sectional expected return literature, we use returns in
} 
Table 7-Predictability of Stock Market Returns and Industry Concentration

Sample

Constant

Forecasted annualized demand growth between $t$ and $t+5$

Forecasted annualized demand growth between $t+5$ and $t+10$

Industry fixed effects

Year fixed effects

Sample: 1974 to 2003

$R^{2}$

$N$

Notes: Columns 1 through 6 report the coefficients of OLS regressions of log yearly beta-adjusted industry stock returns at $t+1$ on the forecasted annualized demand growth due to demographics between $t$ and $t+5$ and between $t+5$ and $t+10$ from 1974 until 2003. The forecast is made using information available as of year $t-1$. The industry betas for year $t$ are obtained by regressing monthly industry returns on market returns for the 48 months previous to year $t$. The coefficients on the forecasted annual demand growth are normalized by the number of years of the forecast (five for both coefficients). The coefficient indicates the typical increase in log industry abnormal stock return due to an annualized 1 percentage point increase in consumption due to demographics. The concentration ratio measure C-4 is the ratio of revenue for the largest four firms to total industry revenue, from the Census of Manufacturers conducted in 1972 (or 1970 if the 1972 measure is missing). Columns 1 through 3 report the results for all industries with a concentration ratio higher than the median. Columns 4 through 6 report the results for all industries with a concentration ratio lower than or equal to the median. Standard errors are clustered by year and then scaled by a function of the autocorrelation coefficient estimated from the sample orthogonality conditions. A more thorough description of the concentration ratio measure and the standard errors is available in the text.

*** Significant at, or below, 1 percent.
** Significant at, or below, 5 percent.
* Significant at, or below, 10 percent.

due to demographics (zero to five years ahead) negatively forecasts returns, but the estimate is not significant. The long-term forecasted demand growth (five to ten years ahead) significantly forecasts abnormal returns, with a point estimate $\hat{\delta}_{1}=7.93$. This point estimate is somewhat larger and more precisely estimated than the estimate with industry and year fixed effects in column 3 of Table 6 , the closest parallel in Table 6. In the context of this methodology, we explore in column 2 a specification that we have not considered elsewhere, with long-term forecasted demand as the only regressor. The point

levels rather than in logs, and the industry betas are computed accordingly. estimate is lower but we still find significant predictability.

In columns 3 through 5, we replicate these results with the unadjusted industry return at $t+1$ as the dependent variable. The point estimates on long-term demand growth are similar and marginally significant when controlling for beta (column 3). When we remove the industry beta, the estimates on long-term demand growth are significant (columns 4 and 5). In columns 6 and 7 , we conduct the same analysis as in columns 1 and 2 for all 48 industries. The point estimates and statistical significance decline slightly, but the qualitative findings are similar to those in columns 1 and 2.

The Fama-MacBeth procedure suggests that there is significant return predictability related 


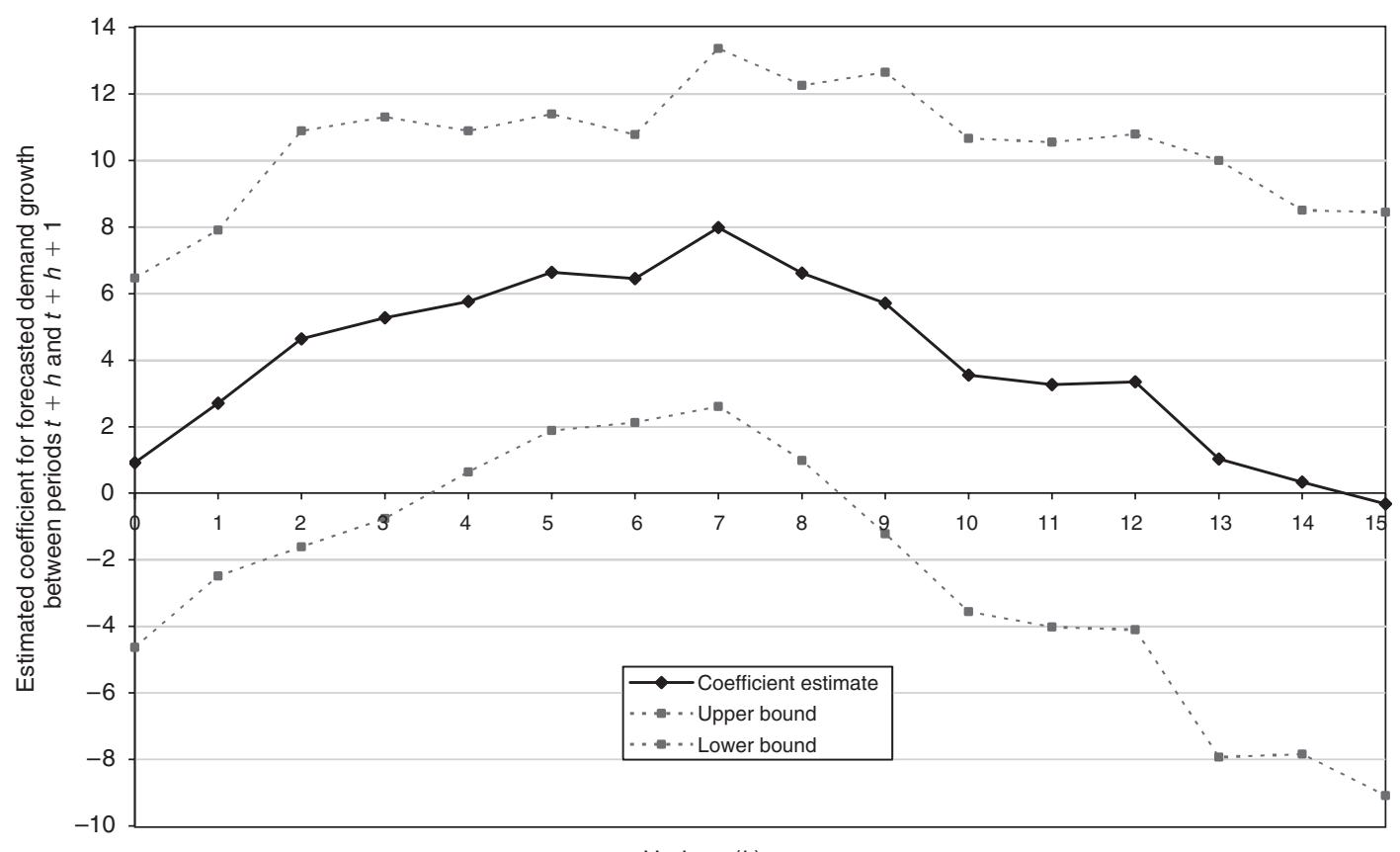

Horizon $(h)$

Figure 4. Return Predictability Coefficient for Demand Growth Forecasts at Different Horizons

Notes: The estimated coefficient for each horizon is from a univariate OLS regression of abnormal returns at $t+1$ on forecasted consumption growth between $t+h$ and $t+h+1$ for the subsample of Demographic Industries over the period 19742003. The confidence intervals are constructed using robust standard errors clustered by year and then scaled by a function of the autocorrelation coefficient estimated from the sample orthogonality conditions.

to long-term demographics after controlling for year effects. The evidence from this alternative approach complements the panel results with industry and year fixed effects in Table 6, which are only marginally significant.

\section{Portfolio Returns}

These results provide evidence of return predictability using long-term demand growth due to demographics. We now analyze whether rational market participants could exploit the underreaction to long-term demographic information with a trading strategy. This provides another measure of the predictability of stock returns induced by underreaction to demographics.

We follow a strategy from 1974 to 2003 for sector indices belonging to the sample of Demographic Industries. We create the zero-investment portfolio by double-sorting the group of industries at the beginning of each year, as suggested by the model. In the presence of inattention with partial extrapolation, both $E_{t}\left[\Delta c_{t+1+h}\right]$ and $E_{t}\left[\Delta c_{t+1+h}-\Delta c_{t+1+h-n}\right]$ will positively predict stock returns. Therefore, we first sort the industries into two equal groups based on long-term forecasted demand growth, $\Delta \hat{c}_{L R} \equiv \hat{c}_{t+10}-\hat{c}_{t+5}$. Next, within each of these two groups, we sort the industries into two equal subgroups based on the difference between long-term and shortterm forecasted growth, that is, $\Delta \hat{c}_{L R-S R} \equiv\left(\hat{c}_{t+10}\right.$ $\left.-\hat{c}_{t+5}\right)-\left(\hat{c}_{t+5}-\hat{c}_{t}\right)$. The zero-investment portfolio is long in industries with high predicted long-term growth $\Delta \hat{c}_{L R}$ and high $\Delta \hat{c}_{L R-S R}$, and is short in industries with low predicted long-term growth $\Delta \hat{c}_{L R}$ and low $\Delta \hat{c}_{L R-S R}$. The portfolio is designed to exploit both inattention to long-term information-measured by $\Delta \hat{c}_{L R}$-and extrapolation一measured by $\Delta \hat{c}_{L R-S R} \cdot{ }^{21}$

${ }^{21}$ An analogous sorting procedure based only on the long-term growth $\Delta \hat{c}_{L R}$ yields portfolio returns that are 
Table 8-Fama-Macbeth Regressions of Returns on Demographic Changes

\begin{tabular}{|c|c|c|c|c|c|c|c|}
\hline \multirow{2}{*}{$\begin{array}{l}\text { Sample } \\
\text { Dependent variable }\end{array}$} & \multicolumn{5}{|c|}{ Demographic industries } & \multirow{2}{*}{\multicolumn{2}{|c|}{$\begin{array}{l}\text { All industries } \\
\text { Beta-adjusted returns } \\
(6)\end{array}$}} \\
\hline & \multicolumn{2}{|c|}{$\begin{array}{l}\text { Beta-adjusted returns } \\
\text { (1) }\end{array}$} & \multicolumn{3}{|c|}{ Unadjusted return } & & \\
\hline Constant & $\begin{array}{c}0.006 \\
(0.055)\end{array}$ & $\begin{array}{c}-0.021 \\
(0.045)\end{array}$ & $\begin{array}{l}0.150 \\
(0.0615)^{* *}\end{array}$ & $\begin{array}{l}0.138 \\
(0.0587)^{* *}\end{array}$ & $\begin{array}{l}0.118 \\
(0.0416)^{* * *}\end{array}$ & $\begin{array}{c}0.004 \\
(0.050)\end{array}$ & $\begin{array}{r}-0.023 \\
(0.041)\end{array}$ \\
\hline Beta & & & $\begin{array}{c}-0.008 \\
(0.038)\end{array}$ & & & & \\
\hline $\begin{array}{l}\text { Forecasted annualized } \\
\text { demand growth between } \\
t \text { and } t+5\end{array}$ & $\begin{array}{c}-3.771 \\
(4.718)\end{array}$ & & $\begin{array}{l}-2.397 \\
(4.856)\end{array}$ & $\begin{array}{l}-3.522 \\
(5.067)\end{array}$ & & $\begin{array}{c}-3.239 \\
(4.620)\end{array}$ & \\
\hline $\begin{array}{l}\text { Forecasted annualized } \\
\text { demand growth between } \\
t+5 \text { and } t+10\end{array}$ & $\begin{array}{l}7.934 \\
(3.3453)^{* *}\end{array}$ & $\begin{array}{l}5.577 \\
(2.0065)^{* * *}\end{array}$ & $\begin{array}{l}6.458 \\
(3.5190)^{*}\end{array}$ & $\begin{array}{l}8.378 \\
(3.1774)^{* * *}\end{array}$ & $\begin{array}{l}5.666 \\
(1.7781)^{* * * *}\end{array}$ & $\begin{array}{l}6.360 \\
(3.3461)^{*}\end{array}$ & $\begin{array}{l}4.828 \\
(1.7371)^{* * *}\end{array}$ \\
\hline Sample: 1974 to 2003 & $\mathrm{X}$ & $\mathrm{X}$ & $\mathrm{X}$ & $\mathrm{X}$ & $\mathrm{X}$ & $\mathrm{X}$ & $\mathrm{X}$ \\
\hline$N$ & $N=30$ & $N=30$ & $N=30$ & $N=30$ & $N=30$ & $N=30$ & $N=30$ \\
\hline
\end{tabular}

Notes: Columns 1 through 7 report the time series averages of the OLS coefficients from 30 cross-sectional regressions of the beta-adjusted industry stock return at year $t+1$ or the unadjusted industry stock return at year $t+1$ on the forecasted annualized demand growth due to demographics between $t$ and $t+5$ and between $t+5$ and $t+10$ from 1974 until 2003. The forecasts are made using information available as of year $t-1$. The industry betas for year $t$ are obtained by regressing monthly industry excess returns on excess market returns for the 48 months previous to year $t$. The coefficients on the forecasted annual demand growth are normalized by the number of years of the forecast (five for both coefficients). Each year the subset of Demographic Industries includes the 20 industries with the highest standard deviation of forecasted annual consumption growth over the next 15 years. Standard errors are based on the time-series variation of the OLS coefficients using a Newey-West estimator with three lags.

*** Significant at, or below, 1 percent.

** Significant at, or below, 5 percent.

* Significant at, or below, 10 percent.

We compute monthly portfolio returns by equally weighting the relevant industry returns. We control for market performance by regressing the series on the CRSP value-weighted stock index, net of the one-month Treasury rate. The standard errors are corrected for heteroskedasticity and autocorrelation using the Newey-West estimator with six lags ${ }^{22}$. The results in column 1 of Table 9 indicate that the portfolio earns a significant monthly abnormal return of 0.55 percent. ${ }^{23}$ The quantitative outperformance remains essentially the same if we also include the size and the book-to-market factors (column 2), as well as the momentum factor (column 3), but the

approximately 10 percent lower in the benchmark specifications (columns 1-3 of Table 9).

${ }^{22}$ The results do not change qualitatively if the lag length for the Newey-West standard errors is 12 .

23 The average monthly return (without a market control) is 0.49 percent (s.e. 0.23 ). statistical significance is only marginal with all four factors (column 3). These magnitudes are consistent with the estimates from the predictability regressions in Table 6 . The annualized abnormal return for the portfolio (6.8 percent) is essentially the same as the product of $\hat{\delta}_{1}(8.91)$ from Table 6 (column 1) and of the average difference between forecasted demand growth from $t+5$ to $t+10$ for the long and short constituent portfolios ( 0.9 percentage points). The outperformance of the zero-investment portfolio depends more heavily on the long portfolio than on the short portfolio (results not shown).

In columns 4 through 7 we report the abnormal performance of the investment strategy for different samples. While we report only the fourfactor results, the results are similar when using a one-factor or three-factor model. For the longer time period 1939-2003 (column 4), the portfolio has an average abnormal annualized return of 4 percent per year (not significant). The lower 
Table 9-Performance of Zero-Investment Portfolio Trading Strategies

\begin{tabular}{|c|c|c|c|c|c|c|c|}
\hline & & Dependent va & riable: Month & return on the & zero-investm & t portfolios & \\
\hline & (1) & (2) & (3) & (4) & (5) & $(6)$ & (7) \\
\hline Constant & $\begin{array}{l}0.005 \\
(0.0023)^{* * *}\end{array}$ & $\begin{array}{l}0.005 \\
(0.0023)^{* *}\end{array}$ & $\begin{array}{l}0.005 \\
(0.0027) *\end{array}$ & $\begin{array}{c}0.003 \\
(0.002)\end{array}$ & $\begin{array}{c}0.002 \\
(0.002)\end{array}$ & $\begin{array}{l}0.007 \\
(0.0025)^{* * * *}\end{array}$ & $\begin{array}{c}0.002 \\
(0.003)\end{array}$ \\
\hline $\begin{array}{l}\text { VW index excess return } \\
\text { (VWRF) }\end{array}$ & $\begin{array}{c}-0.098 \\
(0.074)\end{array}$ & $\begin{array}{r}-0.098 \\
(0.074)\end{array}$ & $\begin{array}{c}-0.102 \\
(0.075)\end{array}$ & $\begin{array}{r}-0.045 \\
(0.056)\end{array}$ & $\begin{array}{l}-0.115 \\
(0.0528)^{* *}\end{array}$ & $\begin{array}{l}-0.124 \\
(0.0634)^{* *}\end{array}$ & $\begin{array}{r}-0.045 \\
(0.082)\end{array}$ \\
\hline $\begin{array}{l}\text { Size factor return } \\
(\mathrm{SMB})\end{array}$ & & $\begin{array}{c}0.158 \\
(0.105)\end{array}$ & $\begin{array}{c}0.160 \\
(0.104)\end{array}$ & $\begin{array}{l}0.192 \\
(0.0928)^{* *}\end{array}$ & $\begin{array}{l}-0.027 \\
(0.089)\end{array}$ & $\begin{array}{l}-0.247 \\
(0.0964)^{* *}\end{array}$ & $\begin{array}{r}-0.083 \\
(0.121)\end{array}$ \\
\hline $\begin{array}{l}\text { Value factor return } \\
\text { (HML) }\end{array}$ & & $\begin{array}{c}0.078 \\
(0.092)\end{array}$ & $\begin{array}{c}0.069 \\
(0.097)\end{array}$ & $\begin{array}{c}0.037 \\
(0.096)\end{array}$ & $\begin{array}{c}0.095 \\
(0.087)\end{array}$ & $\begin{array}{l}-0.068 \\
(0.089)\end{array}$ & $\begin{array}{c}-0.223 \\
(0.143)\end{array}$ \\
\hline $\begin{array}{l}\text { Momentum factor return } \\
\text { (UMD) }\end{array}$ & & & $\begin{array}{l}-0.033 \\
(0.086)\end{array}$ & $\begin{array}{c}0.040 \\
(0.071)\end{array}$ & $\begin{array}{c}0.073 \\
(0.051)\end{array}$ & $\begin{array}{l}0.139 \\
(0.0633)^{* *}\end{array}$ & $\begin{array}{c}0.003 \\
(0.146)\end{array}$ \\
\hline Sample: 1974 to 2003 & $\mathrm{X}$ & $X$ & $\mathrm{X}$ & & $X$ & $\mathrm{X}$ & $\mathrm{X}$ \\
\hline Sample: 1939 to 2003 & & & & $\mathrm{X}$ & & & \\
\hline Demographic industries & $\mathrm{X}$ & $\mathrm{X}$ & $\mathrm{X}$ & $\mathrm{X}$ & & & \\
\hline All industries & & & & & $\mathrm{X}$ & & \\
\hline $\mathrm{C}-4>$ median & & & & & & $\mathrm{X}$ & \\
\hline $\mathrm{C}-4 \leq$ median & & & & & & & $\mathrm{X}$ \\
\hline$R^{2}$ & 0.008 & 0.018 & 0.018 & 0.010 & 0.060 & 0.071 & 0.013 \\
\hline$N$ & $N=360$ & $N=360$ & $N=360$ & $N=780$ & $N=360$ & $N=360$ & $N=360$ \\
\hline
\end{tabular}

Notes: Columns 1 through 7 report the coefficients of OLS regressions of the zero-investment portfolio monthly returns on different sets of monthly benchmark factors. We create the zero-investment portfolio by double sorting a selected set of industries at the beginning of each year. First, we sort these industries into two equal groups based on long-term predicted demand growth. Next, within each of these two groups we sort industries into two equal subgroups based on the difference between predicted long-term and short-term demand growth. The zero-investment portfolio is long in industries with high predicted long-term demand growth and high long-term minus short-term predicted demand growth, and short in industries with low predicted long-term demand growth and low long-term minus short-term predicted demand growth. Columns 1 through 3 report results for Demographic Industries from 1974 to 2003, column 4 reports results for Demographic Industries from 1939 until 2003, and column 5 reports results for All Industries from 1974 until 2003. Column 6 report results for industries with above-median concentration ratios. Column 7 reports results for industries with below-median concentration ratios. Each year the subset of Demographic Industries includes the 20 industries with the highest standard deviation of forecasted annual consumption growth over the next 15 years. The concentration ratio measure is the ratio of revenue for the largest four firms to total industry revenue, from the 1972 Census of Manufacturers (or 1970 Census if the 1972 value is missing). VWRF is the return on the CRSP value-weighted stock index minus the one-month Treasury rate. SMB and HML are the returns on the Fama-French factor-mimicking portfolios for size and book-to-market, respectively. UMD is the return on the factor-mimicking portfolio for momentum. Heteroskedasticity and autocorrelation consistent standard errors are calculated using the Newey-West estimator with six lags (in parentheses). The constant is interpreted as the average monthly abnormal return for the investment strategy.

*** Significant at, or below, 1 percent.

** Significant at, or below, 5 percent.

* Significant at, or below, 10 percent.

abnormal returns during this longer time period are consistent with the OLS findings in Table 6. At the beginning of the sample period, fewer of the industries most affected by demographics (the Young group) are present, and each industry contains significantly fewer firms. Column 5 reports the results for a similar zero-investment portfolio constructed using all 48 industries for 
the years 1974-2003. This portfolio earns an average annual abnormal return of 2.7 percentage points. The insignificant performance of the portfolio strategy in this sample is roughly consistent with the OLS results in Table 6, because the difference between average forecasted longterm demand growth for industries in the long portfolio and the short portfolio is only 0.5 percentage points.

In columns 6 and 7 we split the overall sample into above-median and below-median concentration industries. The average abnormal return for the high-concentration sample is 8.2 percent per year and is statistically significant. The portfolio return for the low-concentration sample, instead, is 3 percent per year and is insignificant. Abnormal returns are more sensitive to forecasted demand growth for more concentrated industries, a finding consistent with the OLS results (Table 7).

The average abnormal returns from trading on demographic information are sizeable. The estimates from the predictability regressions and the abnormal returns for the trading strategy are consistent with each another.

\section{Explanations}

Three findings emerge from the analysis of industry stock returns. First, forecastable demand changes due to demographics predict abnormal stock returns. Second, while demographic changes in the more distant future $(t$ +5 to $t+10$ ) forecast returns, demographic changes in the near future $(t$ to $t+5)$ do not have significant forecasting power. Third, return predictability appears to be stronger in industries with higher concentration ratios (a proxy for high barriers to entry).

These findings are not consistent with our baseline model of fully rational investors. According to Prediction 1 in Section I, if investors are rational, then abnormal stock returns should not be forecastable using expected demand changes. In this section, we consider a series of alternative explanations.

\section{A. Rational Explanations}

Rational Predictability.-Demographic variables predict expected market returns according to Geanakoplos, Magill, and Quinzii (2004). Hence, demographics could be a state variable that alters the future investment opportunities. According to the Intertemporal Capital Asset Pricing Model (ICAPM) (Robert C. Merton 1973), demographics may then also generate cross-sectional return predictability. Essentially, news about demographics could be a risk factor that is not captured by our specification.

However, the pattern of our predictability findings are harder to fit with this explanation. The omitted demographic factor would need to be unrelated (or negatively related) to the demand forecasts from $t$ to $t+5$, but positively related to the demand forecasts from $t+5$ to $t$ +10 . It is not clear how a risk-factor explanation would have these properties. In addition, we can directly test whether the time-series demographic variables that predict market returns in Geanakoplos, Magill, and Quinzii (2004) affect the industry predictability results in Table 6 . Including these aggregate variables as controls does not affect the return predictability results (results not shown).

Poor Estimation of Systematic Risk.-For the specifications in Tables 6 and 7, the industry beta is estimated using the previous 48 months of industry returns. If the actual beta increases for industries with high demand growth rates five to ten years in the future, then the estimated beta understates the actual systematic risk. This estimation problem could explain the observed outperformance. To test for this, we regress annual changes in estimated beta, $\hat{\beta}_{k, t+1}-\hat{\beta}_{k, t}$, on forecasted short-term and long-term demand growth. We find no significant relationship between changes in estimated beta and longterm demand growth.

Persistent Regressors.-The predictability results could suffer from bias from persistent regressors. Following Robert F. Stambaugh (1999), assume that demand growth due to demographics, denoted $x$, follows an AR(1) process, $x_{t}=\theta+\rho x_{t-1}+v_{t}$, with $|\rho|<1$. Denote by $\sigma_{v}^{2}$ the variance of $v$ and by $\sigma_{\varepsilon v}$ the covariance between $v_{t}$ and $\varepsilon_{t}$, the error term in (9). Stambaugh shows that the bias in the estimate of $\hat{\delta}_{1}$ is approximately equal to $\mathrm{E}\left(\hat{\delta}_{1}-\delta_{1}\right)=$ $-\left(\sigma_{\varepsilon v} / \sigma_{v}^{2}\right)(1+3 \rho) / T$, where $T$ is the number of observations. 
To evaluate the seriousness of this problem, we estimate $\hat{\rho}$ and $\hat{v}_{k, t}$ by a panel regression of the five to ten year growth rate due to demographics $x_{k, t}$ on its lagged value $x_{k, t-1}$ for the benchmark sample. We include industry fixed effects and assume that $\rho_{k}=\rho$ for each industry $k$. We obtain a point estimate for $\hat{\rho}$ of 0.896 , with a standard error of 0.021 . We use this to generate the series for $\hat{v}_{k, t}$. We then regress the estimated errors $\hat{\varepsilon}_{k, t}$ from the return regression (including industry indicators) on the series $\hat{v}$, again including industry fixed effects. We obtain an estimate for $\sigma_{\varepsilon v} / \sigma_{v}^{2}$ of -10.08 (s.e. 13.17). First, this estimate is not statistically different from zero and, consequently, we fail to reject the null hypothesis of no bias. Second, using the expression above, we bound the approximate bias with $(-10.08) *(1$ $+3 \rho) / 569 \geq(-10.08) * 4 / 569=-0.07$, a small correction relative to the 11.30 estimate for $\hat{\delta}_{1}$. The persistence of regressors does not appear to be a main concern in our setting.

Generated Regressors.-In the predictability regressions, the forecasted demand growth rates are estimated using demographic and consumption data. In general, the standard errors should be corrected for the uncertainty in these preliminary estimates. However, Adrian R. Pagan (1984) shows that the standard errors do not require adjustment under the null hypothesis that the generated regressors do not have any predictive power- the null hypothesis evaluated in the paper.

\section{B. Behavioral Explanations}

Incorrect Beliefs about Firm Entry and Exit Decisions.-Investors may correctly understand the impact of demographics on demand, but incorrectly expect that the profits due to demand will be dissipated by firm entry and exit. Hence, investors respond to the demand shift only when it affects earnings. This explanation, however, suggests, counterfactually, that the short-term demand growth due to demographics should positively predict stock returns, while the longterm demand should be unrelated to returns.

The converse explanation would be that investors overestimate the impact of demographics on profitability because they do not take into account entry and exit. In this case, they would be consistently disappointed when profits fail to meet expectations. According to this explanation, short-term demographic growth should forecast returns negatively, for which there is limited evidence in the data. This story would, however, not generate predictability with long-term demographics, unless investors also respond slowly to demographic information.

Short Asset Manager Horizons.-Money managers are usually evaluated based on short-term performance. These managers may not be able to hold positions long enough to reap the returns from trading on long-term information. However, the trading strategy on demographics has substantial abnormal returns even at an annual frequency. These returns should be relevant even for professionals with relatively short investment horizons.

Neglect of Slowly Moving Variables.-In the frenzy of earnings announcements, liquidity-driven orders, and media headlines, investors may disregard variables that display little daily variation, like demographics. Studies on just-noticeable differences (E. H. Weber 1834) suggest a minimum size of a stimulus necessary for detection, let alone to attract attention. Demographic information may therefore be neglected until the information is incorporated in earnings announcements, which are discrete events. This hypothesis could explain the stock return forecastability, but not its horizon. This story suggests that short-horizon, rather than long-horizon, demographic information should predict stock returns.

\section{Attention Explanation}

Prediction 2 in Section I offers an explanation of return predictability based on inattention. If investors neglect information beyond a particular horizon $h$, then returns at $t+1$ should be predictable using long-term demographic information emerging between $t+h$ and $t+1+h$. The results in Tables 6 through 9 suggest that the horizon $h$ could be between five and ten years. Figure 4 shows that stock return predictability is significant using predicted consumption growth between four and eight years ahead. Since demographic information is measured in July rather than at the end of the year, these 
findings suggest that investors have a horizon between 3.5 and 7.5 years.

This estimated horizon for investors is consistent with the observed horizon of analyst forecasts estimated from I/B/E/S data. Out of 4,144 companies with forecast data available in year $1990,96.3$ percent have at least one forecast of earnings two years ahead. However, only 47.3 percent have forecasts three years ahead and fewer than 10 percent have forecasts five years ahead. Forecasts beyond five years are not even reported in the dataset in 1990. These figures are similar in year 2000, and are only slightly higher for larger companies. ${ }^{24}$ According to $\mathrm{I} / \mathrm{B} / \mathrm{E} / \mathrm{S}$, therefore, analysts do not produce forecasts of annual earnings beyond five years. While longterm forecasts may be available in privately held data sources, most investors are unlikely to possess information regarding profitability in the distant future. Given this evidence, it would not be surprising if investors tend to ignore outcomes more than five years in the future.

The model in Section I also makes a prediction regarding the coefficient on long-term forecasted demand growth in the return predictability regressions (Table 6 ). The estimate, $\hat{\delta}_{1} \approx 8.9$, is 3.3 times larger than $\hat{\theta} \approx 2.7$, the estimate for the responsiveness of accounting return on equity to forecasted demand growth (Table 4). These magnitudes are not consistent with a model of unconditional inattention $(w=1)$ which predicts that $\delta_{1}$ should be smaller than $\theta: \delta_{1}=\rho^{h} \theta<\theta$. However, a model of inattention with partial extrapolation $(w<1)$ can match the estimated magnitude of

${ }^{24}$ Details are in Table 11 of DellaVigna and Pollet (2005). $\delta_{1}$. For example, set the annual discount factor $\rho$ equal to 0.96 , the extrapolation weight $w$ equal to 0.5 , and the number of periods of extrapolation $n$ equal to 4 . For these parameters the model of inattention with partial extrapolation implies $\delta_{1}$ $=\theta \rho^{h}[1+(1-w) \rho /((1-\rho) n)] \approx 3.3 \theta$ when the horizon $h$ is equal to five years.

\section{Conclusion}

We present evidence relating demographic variables to consumption patterns, industry profitability, and stock returns for 48 industries. Different goods have substantially dissimilar age patterns of consumption. Forecastable shifts in cohort size by age enable us to produce forecasts of demand growth due to demographic changes. The forecasted demand growth due to demographics predicts the contemporaneous industry-level accounting return on equity, the measure of profitability.

We examine when the forecastable change in profits is incorporated into stock prices. The evidence suggests that long-term growth rates of demand predict annual abnormal returns, while short-term growth rates do not have significant forecasting power. This predictability result is less pronounced when controlling for year fixed effects.

We present a set of rational and behavioral explanations for the findings. While we cannot exclude the possibility that our findings are due to an omitted risk factor, our preferred explanation is that investors are short-sighted and neglect information beyond a horizon of four to eight years.

\section{Appendix A: Model}

The first-order condition for each firm in a symmetric equilibrium is

$$
P^{\prime}\left[\frac{N q^{*}}{\alpha}\right] \frac{q^{*}}{\alpha}+P\left[\frac{N q^{*}}{\alpha}\right]-c^{\prime}\left(q^{*}\right)=0 .
$$

For a given $\alpha$ and $N$ in the second stage, equation (10) has a unique solution. This follows because the left-hand side of equation (10) is decreasing in $q^{*}$, is positive for $q^{*}=0$, and is negative in the limit as $q \rightarrow \infty$. We consider the impact of a short-run increase in demand $\alpha$.

LEMMA 1: For a given $N$ : (i) production increases at most proportionally with the demand shift: 0 $<\partial q^{*}(\alpha) / \partial \alpha \leq q^{*}(\alpha) / \alpha$; (ii) if $c^{\prime}()=$.$c , production increases proportionally with the demand shift:$ $\partial q^{*}(\alpha) / \partial \alpha=q^{*}(\alpha) / \alpha$. 


\section{PROOF:}

Without loss of generality, consider a short-run increase from $\alpha_{0}$ to $\alpha_{1}>\alpha_{0}$. (i) First, we show $q^{*}\left(\alpha_{1}\right)>q^{*}\left(\alpha_{0}\right)$. Since the first-order condition is satisfied for $q=q^{*}\left(\alpha_{0}\right)$ and $\alpha=\alpha_{0}$, the left-hand side of (10) is positive for $q=q^{*}\left(\alpha_{0}\right)$ and $\alpha=\alpha_{1}$. The left-hand side of (10) would be more positive for smaller $q$, and thus $q^{*}\left(\alpha_{1}\right)>q^{*}\left(\alpha_{0}\right)$. Second, we show $q^{*}\left(\alpha_{1}\right) \leq \alpha_{1} q^{*}\left(\alpha_{0}\right) / \alpha_{0}$. The first-order condition implies that the left-hand side of (10) is (weakly) negative for $q=\alpha_{1} q^{*}\left(\alpha_{0}\right) / \alpha_{0}$ and $\alpha=\alpha_{1}$. The left-hand side of (10) would be more negative for larger $q$, and thus $q^{*}\left(\alpha_{1}\right) \leq \alpha_{1} q^{*}\left(\alpha_{0}\right) / \alpha_{0}$. We rewrite $q^{*}\left(\alpha_{0}\right)<q^{*}\left(\alpha_{1}\right) \leq \alpha_{1} q^{*}\left(\alpha_{0}\right) / \alpha_{0}$ as $0<\left(q^{*}\left(\alpha_{1}\right)-q^{*}\left(\alpha_{0}\right)\right) /\left(\alpha_{1}-\alpha_{0}\right) \leq q^{*}\left(\alpha_{0}\right) / \alpha_{0}$, and $0<\partial q^{*}(\alpha) / \partial \alpha$ $\leq q^{*}(\alpha) / \alpha$ follows for $\alpha_{1} \rightarrow \alpha_{0}$. (ii) Assume that $c^{\prime}()=$.$c . For q=\alpha_{1} q^{*}\left(\alpha_{0}\right) / \alpha_{0}$ and $\alpha=\alpha_{1}$, the firstorder condition is satisfied. Hence, $q^{*}\left(\alpha_{1}\right)=\alpha_{1} q^{*}\left(\alpha_{0}\right) / \alpha_{0}$ is the solution and $\partial q^{*}(\alpha) / \partial \alpha=q^{*}(\alpha) / \alpha$ follows.

PROOF OF CLAIM 1:

The derivative of $R O E$ with respect to a demand change $\alpha$ is

$$
\frac{\partial R O E}{\partial \alpha}=\frac{1}{K}\left(P^{\prime}\left[\frac{N q^{*}}{\alpha}\right]\left(\frac{\partial q^{*}}{\partial \alpha}-\frac{q^{*}}{\alpha}\right)\left(\frac{N q^{*}}{\alpha}\right)+\left(P\left[\frac{N q^{*}}{\alpha}\right]-c^{\prime}\left(q^{*}\right)\right) \frac{\partial q^{*}}{\partial \alpha}\right)>0
$$

where the inequality uses (i) $0 \leq \partial q^{*}(\alpha) / \partial \alpha \leq q^{*}(\alpha) / \alpha$ from the lemma, (ii) $P^{\prime}()<$.0 , and (iii) $P\left(N q^{*} / \alpha\right)>c^{\prime}\left(q^{*}\right)$ by (10). Therefore, ROE is increasing in the demand shift $\alpha$ in the short-run and the short-run elasticity $\theta_{S R}=\partial(1+R O E) / \partial \alpha^{*}(\alpha /(1+R O E))$ is positive. If marginal costs are constant $c(q)=c q$, the lemma states that $\partial q^{*}(\alpha) / \partial \alpha=q^{*}(\alpha) / \alpha$. Hence, the short-run elasticity is

$$
\theta_{S R}=\frac{1}{K}\left(\left(P\left[\frac{N q^{*}}{\alpha}\right]-c^{\prime}\left(q^{*}\right)\right) \frac{q^{*}}{\alpha}\right) \alpha\left(\frac{K}{\pi+K}\right)=\frac{\pi}{\pi+K}
$$

\section{APPENDIX B: DATA}

\section{Demographic Forecasts}

Cohort Size Adjustment.-The cohort size data are from the Current Population Reports, Series 25. For the years before 1980, these series lump together all age groups above the age of 84. In order to match the cohort sizes with the mortality rates, we disaggregate the group of age $85+$ into one-year age groups using the relative cohort sizes in 1980. Let $A_{g, j, t}$ be the population size at age $j$ for gender $g$ in year $t$. For any $t<1980$, we impute population sizes for ages 85 to 99 using $A_{g, j, t}=$ $\left(\sum_{j=85}^{99} A_{g, j, t} / \sum_{j=85}^{99} A_{g, j, 1980}\right) * A_{g, j, 1980}$. This imputation imposes a constant population distribution in each year for ages beyond 84. (In the years before 1940, the series lump together age groups above 74. We apply the same imputation procedure using the age distribution of 1940 up to age 84 and the age distribution of 1980 beyond age 84.) Therefore, forecasts of population growth for ages beyond 84 will not match the imputed age distribution in the following year. Given the small size of population above 84 years of age (2,197,000 individuals in 1979), this issue is unlikely to matter.

Mortality Rate Adjustment.-We use the mortality rates from period life tables in Life Tables for the United States Social Security Area 1900-2080. To adjust for improvements in mortality rates over time, we compute a mortality-rate adjustment for each ten-year age range using data from the previous five decades. The adjustment coefficient is allowed to differ by ten-year age groups. Let $q_{g, j, d}$ be the mortality rate for gender $g$, age $j$, and decade $d$ from the life tables and let $d(t)$ be the end of the most recent decade before $t$. If $t=1951$, then the mortality adjustment for ages 10 to 19 is based on 
the coefficient $\left(\kappa_{[10,19], 1951}\right)$ from the regression $q_{g, j, d}=\kappa_{[10,19], 1951} * q_{g, j, d-1}+\varepsilon_{g, j, d}$ for all observations with $d \in\{1910,1920,1930,1940,1950\}$ and $10 \stackrel{\leq}{\leq} \leq 19$. The estimated percentage improvement in mortality rates for the ages $10-19$ is about 20 percent per decade. Therefore, $\hat{q}_{g, j, u}$, the forecast from year $t$ of mortality rates at age $j$ in year $u>t$, is given by $\hat{q}_{g, j, u \mid t}=q_{g, j, d(t)} *\left(\kappa_{z(j), t}\right)^{(u-t) / 10}$, where $z(j)$ is the 10-year age range corresponding to age $j$.

Fertility. - We take the fertility rate by one-year age of the mother from Heuser (1976) and update it for the more recent years using the Vital Statistics of the United States: Natality. We assume that the forecasted fertility rate $\hat{b}_{j, u \mid t}$ for women of age $j$ in year $u$, forecasted as of year $t$, equals the actual fertility rate $b_{j, t \mid t}$ for women of age $j$ in year $t: \hat{b}_{j, u \mid t}=b_{j, t \mid t}$. For data availability reasons, the fertility rate after the year 2000 is assumed to equal fertility in the year 2000.

Cohort Size Forecast.-By combining the present population profile with the forecasts of mortality and fertility, we produce a preliminary forecast of the future population profile with an iterative procedure. Starting with the preliminary population profile $\hat{A}_{g, u-1 \mid t}^{p}=\left[\hat{A}_{g, 0, u-1 \mid t}^{p}, \hat{A}_{g, 1, u-1 \mid t}^{p}, \hat{A}_{g, 2, u-1 \mid t}^{p}, \ldots\right]$ for year $u-1$, we generate a forecasted population profile for the next year $u$ using two relationships. First, for any age $j \geq 1$, we calculate $\hat{A}_{g, j, u \mid t}^{p}$ as $\hat{A}_{g, j, u \mid t}^{p}=\hat{A}_{g, j-1, u-1 \mid t}^{p} *\left(1-\hat{q}_{g, j-1, u-1 \mid t}\right)$. Second, the forecast number of newborns in year $u$ (age 0) is given by $\hat{A}_{g, 0, u \mid t}^{p}=s r_{g}^{*} \sum_{j=14}^{49} \hat{A}_{f, j, u-1 \mid t}^{p} * \hat{b}_{j, u-1 \mid t}$, where $s r_{m}$ $=0.501$ is the average probability that a newborn will be male ( $s r_{f}=1-s r_{m}$ by construction).

Immigration Adjustment.-We compute a backward-looking adjustment for net migration by regressing the percentage difference between the actual cohort size and the preliminary forecasted cohort size formed the year before, on a constant. We produce these adjustment coefficients separately for each ten-year age group using data from the most recent five-year period prior to year $t$. (For the age group 0-9, we allow for a separate adjustment coefficient for age 1, and do not adjust the forecast for the unborn.) For instance, if $t=1951$, then the immigration adjustment for ages 10 to 19 is based on the coefficient $\left(\psi_{[10,19], 1951}\right)$ from the regression $\left(A_{g, j, t-i+1}-\hat{A}_{g, j, t-i+1 \mid t-i}\right) / \hat{A}_{g, j, t-i+1 \mid t-i}^{p}=\psi_{[10,19], 1951}$ $+\nu_{g, j, t-i}$ for all observations with $0 \leq i \leq 5$ and $10 \leq j \leq 19$. For this age group, the average imputed net migration is about 0.4 percent per year. We apply this adjustment for migration to the initial population forecasts made at time $t$. Therefore, $\hat{A}_{g, j, u \mid t}$, the forecast of cohort size for gender $g$ and age $j$ in year $u$ as of year $t$, is given by $\hat{A}_{g, j, u \mid t}=\hat{A}_{g, j, u \mid t}^{p} * \prod_{i=1}^{u-t}\left(1+\psi_{z(j-i), t}\right)$, where the function $z$ converts $j-i$ to an age range. (The forecasts for the unborn are obtained by applying the adjustment coefficient to the mothers, computing the forecasted number of births, and aging the cohort.) The forecasted cohort size profile $\hat{A}_{g, u \mid t}=\left[\hat{A}_{g, 0, u \mid t}, \hat{A}_{g, 1, u \mid t}, \hat{A}_{g, 2, u \mid t}, \ldots\right]$ is the basis for the empirical analysis in the paper.

\section{Consumption Data}

Consumption Surveys.-The sample sizes and sampling rules differ across surveys. While the postwar surveys cover a representative sample of the US population, the 1935-1936 survey includes only married couples and is therefore biased toward younger families. ${ }^{25}$

Expenditure Categories.-The dependent variable in the regressions in Section IIB is the yearly expenditure, $c_{i, k, t}$, on each category $k$ listed in Appendix Table 1. In particular, the automobile and motorcycle categories include expenditures on both new and used vehicles. The coal category includes expenditure on both coal and electricity. The health care and medical equip-

\footnotetext{
${ }^{25}$ Appendix Table 1 in DellaVigna and Pollet (2005) presents summary statistics about demographics in the four surveys.
} 
ment categories are estimated using total expenditure on health, including health insurance. The health insurance category, instead, is limited to health insurance expenditure. The residential mortgage category is estimated using expenditure on mortgage interest. The utilities category includes expenditure on electricity, water, and natural gas. An issue arises when a consumer survey does not provide expenditure information about a category. In this case, the age-consumption profile is estimated using a prior consumption survey. For example, since no detailed information on the three book categories is available in 1960-1961, we use the data from 1935-1936 instead.

Housing.-The residential development category is estimated using the housing value. For some of the observations, the information on housing value is not available for renters. In this case, we compute an implicit conversion rate from yearly rent to housing value for the sample for which both measures are available, and apply it to the yearly rent value. The conversion rate from yearly rent to housing value equals $1 / 0.028$ in $1936-37,1 / 0.088$ in $1972-73$, and $1 / 0.076$ in $1983-84$. Since the conversion rate for 1960-1961 cannot be computed, we use the rate for 1972-1973. The expenditures for residential construction and for construction equipment, which depend on changes in the housing stock, rather than on levels, is computed differently. First, we compute the forecasted housing value $\hat{C}_{\text {housing, } u \mid t}$ for year $u$, given information of year $t$. Then we compute the forecasted demand for residential construction and construction equipment as $\hat{C}_{\text {housing, } u \mid t}-\hat{C}_{\text {housing, } u-1 \mid t}+0.1 \hat{C}_{\text {housing, } u-1 \mid t}$, that is, the change in the forecasted housing stock plus housing depreciation.

Other Issues. - Income and housing value in the 1960-1961 survey is reported in discrete categories. We assign it the mean value in the category, and 1.5 times the value for the top category. Housing value is top-coded in the 1983-1984 survey. We use the 1972-1973 category to compute the adjustment coefficient of 1.53. Finally, for the households in the 1983-1984 survey that are interviewed for fewer than four quarters, we compute an annualized consumption value.

\section{Industry Classification}

The industry classification system is designed to satisfy three basic criteria: (a) aggregate goods with a relatively homogeneous age profile of consumption; (b) define categories that are consistent over time; (c) minimize deviations from the SIC. These criteria lead to 48 industries (Appendix Table 1) belonging to three groups.

Standard industries - such as oil, telephone, and health insurance-are constructed from a list of four-digit SIC codes. For example, the health insurance industry is defined by the SIC codes 6320-6329. A company belongs to industry $k$ in year $t$ if its SIC code for year $t$ coincides with one of the listed codes for industry $k$. In Appendix Table 1 these industries are characterized by the absence of codes in parentheses. The classification for these industries closely resembles the Fama-French classification.

Searched industries - such as toys, cruises, and furniture-are also constructed on the basis of a list of four-digit SIC codes. In addition, we eliminate the companies in these SIC codes whose core business does not belong in the industry (from our standpoint). For example, we eliminate golf equipment manufacturers and retailers from the toys industry. Further, we define a list of additional SIC codes and identify companies in these codes that belong to the industry. The searched industries are identifiable in Appendix Table 1 by the presence of SIC codes without parentheses (the basic codes) and with parentheses (the additional codes).

Reclassified industries - the book industry subcategories, as well as golf, motorcycles, and bicycles-are not uniquely associated with any SIC codes. Companies in these industries are identified from within a list of SIC codes. For example, in order to construct the four book categories, we search the SIC codes 2730-2739 and determine the companies whose core business consists of books for children, books for $\mathrm{K}-12$, etc. In Appendix Table 1 these expenditure categories have SIC codes in parentheses. 
Appendix Table 1-Industries and Their Standard Industrial Classification (SIC) Codes

\begin{tabular}{|c|c|c|}
\hline Expenditure category & Grouping & Standard Industrial Classification codes \\
\hline Child care & Children & $8350-8359$ \\
\hline Children’s books & Children & $(2730-2739)$ \\
\hline Children's clothing & Children & $2360-2369,5640-5649,(5130,5137)$ \\
\hline Toys & Children & (3940), 3941-3948, (3949), (5090), 5092, (5940), 5945, (6711), (7990) \\
\hline Books: college text books & Media & $(2730-2739)$ \\
\hline Books: general & Media & $5942,(2720-2739,5192)$ \\
\hline Books: K-12 school books & Media & $(2720-2739)$ \\
\hline Movies & Media & $7810-7819,7820-7849$ \\
\hline Newspapers & Media & $2710-2719,(5192)$ \\
\hline Magazines & Media & $2720-2729,(2730-2739,5192)$ \\
\hline Cruises & Health & $4480-4481,(4410,4411,7990,7999)$ \\
\hline Dental equipment & Health & $3843,8020-8029,(3840,5047,8090)$ \\
\hline Drugs & Health & $2830-2839,5120-5129(8090)$ \\
\hline Health care (services) & Health & $8000-8019,8030-8049,(8050-8059), 8060-8071,(8072), 8080-8089,(8090-8092)$ \\
\hline Health insurance & Health & $6320-6329$ \\
\hline Medical equipment & Health & $3840-3842,3844-3849,5047,(5040,5120-5129,8090)$ \\
\hline Funeral homes and cemet. & Seniors & $3995,7260-7269,(3990,6550,6553)$ \\
\hline Nursing home care & Seniors & $8050-8059,(6510,6513,6798,8080-8089,8360-8361)$ \\
\hline Construction equipment & House & $3531,5031-5039,5210-5259,(3530,5080,5082)$ \\
\hline Floors & House & $2270-2279,5713,(5020,5710,5719)$ \\
\hline Furniture & House & $2510-2519,5021,5712(5020,5710,5719)$ \\
\hline Home appliances, big & House & $3631-3633,3639,5720-5729(3630,3651,5060,5075,5078)$ \\
\hline Home appliances, small & House & $3634,(3630,3645,5020,5023,5060)$ \\
\hline Housewares & House & $3262,3263,3914,(3260,3269,3910,5944,5719)$ \\
\hline Linens & House & $2391-2392,5714,(2390,5020,5710,5719)$ \\
\hline Residential construction & House & $1520-1529,(1540-1549)$ \\
\hline Residential development & House & $6513,6530-6539,6552,(1520-1529,6510,6550)$ \\
\hline Residential mortgages & House & $6160-6169$ \\
\hline Beer (and wine) & Perishable & $2082,2083,2084,5181,(2080,2084,2085,5180,5182,5813)$ \\
\hline Cigarettes & Perishable & $2100-2119$ \\
\hline Cigars and other tobacco & Perishable & $2120-2199$ \\
\hline Food & Perishable & 0100-0299, 2000-2079, 2086, 2087, 2090-2099, 5140-5149, 5400-5499, 5812 (5810) \\
\hline Liquor & Perishable & $2085(2080,2084,5180,5182,5810,5813,5920-5921)$ \\
\hline Clothing (adults) & Clothing & $2310-23495136,5137,5610-5619,(5130), 5136$ \\
\hline Cosmetics & Clothing & $2844,7231,(2840,5120,5122,5130)$ \\
\hline Golf & Clothing & $(2320,2329,3940,3949,5090,5130,5940,7990,7999)$ \\
\hline Jewelry & Clothing & $3911,3915,5944,(3910,5090,5094,5940)$ \\
\hline Sporting equipment & Clothing & $3949,5941,(2320,2329,2390,3940-3948,5090-5091,5130,5940,5945,7999)$ \\
\hline Life insurance & Insurance & $6310-6319$ \\
\hline Property insurance & Insurance & $6330-6339$ \\
\hline Airplanes & Transport & $3720-3729,4511-4512,(4510,4513)$ \\
\hline Automobiles & Transport & $3010-3019,3710-3719,5010-5019,5510-5529$ \\
\hline Bicycles & Transport & $(3710,3750-3759,3714,5090)$ \\
\hline Motorcycles & Transport & $(3750-3759,3571)$ \\
\hline Coal & Utilities & $1200-1299$ \\
\hline Oil & Utilities & 1300-1399, 2910, 2911 \\
\hline Telephone & Utilities & $4810-4811,4813-4819$ \\
\hline Utilities & Utilities & 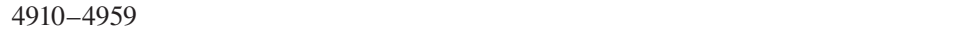 \\
\hline
\end{tabular}

Notes: Complete list of expenditure categories (column 1) with industry grouping (column 2) and SIC industry classification (column 3). Each expenditure category is associated with two sets of codes. The first set of codes (not in parentheses) corresponds to the four-digit SIC codes that are uniquely identified with one category. The second set of codes (in parentheses) identifies the SIC codes that are explicitly associated with multiple categories or have a large number of misclassified companies. Randomly selected companies within each SIC code are searched to determine if a SIC code has many misclassified companies or multiple expenditure categories. All companies in each SIC code listed in parentheses are subjected to an Internet search to determine their expenditure category classification. If the Internet search cannot identify the specific category for one of these companies, the company is excluded from our analysis. 


\section{ApPEndix C: StANDARD ERrors}

Define $\boldsymbol{\Gamma}_{q}=\mathrm{E}\left[\left(\sum_{k=1}^{K} \boldsymbol{X}_{k t} \boldsymbol{\varepsilon}_{k t}\right)^{\prime}\left(\sum_{k=1}^{K} \boldsymbol{X}_{k t-q} \boldsymbol{\varepsilon}_{k t-q}\right)\right]$ and assume $\boldsymbol{X}_{k t}^{\prime} \boldsymbol{\varepsilon}_{k t}=\rho \boldsymbol{X}_{k t-1}^{\prime} \boldsymbol{\varepsilon}_{k t-1}+\boldsymbol{\eta}_{k t}^{\prime}$, where $\rho<$ 1 is a scalar and $\mathrm{E}\left[\left(\sum_{k=1}^{K} \boldsymbol{X}_{k t-q} \boldsymbol{\varepsilon}_{k t-q}\right)^{\prime}\left(\sum_{k=1}^{K} \boldsymbol{\eta}_{k t}\right)\right]=\mathbf{0} \forall q>0$. Then,

$$
\begin{aligned}
\boldsymbol{\Gamma}_{q} & =\mathrm{E}\left[\left(\sum_{k=1}^{K}\left(\rho^{q} \boldsymbol{X}_{k t-q} \boldsymbol{\varepsilon}_{k t-q}+\sum_{j=1}^{q} \rho^{q-j} \boldsymbol{\eta}_{k t-q+j}\right)\right)^{\prime}\left(\sum_{k=1}^{K} \boldsymbol{X}_{k t-q} \boldsymbol{\varepsilon}_{k t-q}\right)\right] \\
& =\mathrm{E}\left[\left(\sum_{k=1}^{K} \rho^{q} \boldsymbol{X}_{k t-q} \boldsymbol{\varepsilon}_{k t-q}\right)^{\prime}\left(\sum_{k=1}^{K} \boldsymbol{X}_{k t-q} \boldsymbol{\varepsilon}_{k t-q}\right)\right]+\mathrm{E}\left[\left(\sum_{j=1}^{q} \rho^{q-j} \sum_{k=1}^{K} \boldsymbol{\eta}_{k t-q+j}\right)^{\prime}\left(\sum_{k=1}^{K} \boldsymbol{X}_{k t-q} \boldsymbol{\varepsilon}_{k t-q}\right)\right] \\
& =\rho^{q} \mathrm{E}\left[\left(\sum_{k=1}^{K} \boldsymbol{X}_{k t-q} \boldsymbol{\varepsilon}_{k t-q}\right)^{\prime}\left(\sum_{k=1}^{K} \boldsymbol{X}_{k t-q} \boldsymbol{\varepsilon}_{k t-q}\right)\right]=\rho^{q} \boldsymbol{\Gamma}_{0} .
\end{aligned}
$$

Using the relationship for $\boldsymbol{\Gamma}_{q}$, we obtain

$$
\boldsymbol{S}=\boldsymbol{\Gamma}_{0}+2 \sum_{q=1}^{\infty} \rho^{q} \boldsymbol{\Gamma}_{0}=\left(2 \sum_{q=0}^{\infty} \rho^{q}-1\right) \boldsymbol{\Gamma}_{0}=\left(\frac{2}{1-\rho}-\frac{1-\rho}{1-\rho}\right) \boldsymbol{\Gamma}_{0}=\left(\frac{1+\rho}{1-\rho}\right) \boldsymbol{\Gamma}_{0} .
$$

\section{REFERENCES}

Abel, Andrew B. 2003. "The Effects of a Baby Boom on Stock Prices and Capital Accumulation in the Presence of Social Security." Econometrica, 71(2): 551-78.

Acemoglu, Daron, and Joshua Linn. 2004. "Market Size in Innovation: Theory and Evidence from the Pharmaceutical Industry." Quarterly Journal of Economics, 119(3) 1049-90.

Ang, Andrew, and Angela Maddaloni. 2005. "Do Demographic Changes Affect Risk Premiums? Evidence from International Data." Journal of Business, 78(1) 341-79.

Bakshi, Gurdip S., and Zhiwu Chen. 1994. "Baby Boom, Population Aging, and Capital Markets." Journal of Business, 67(2): 165-202.

Barber, Brad M., and Terrance Odean. Forthcoming. "All that Glitters: The Effect of Attention and News on the Buying Behavior of Individual and Institutional Investors." Review of Financial Studies.

Bell, Felicitie C., Alice H. Wade, and Stephen C. Goss. 1992. "Life Tables for the United States Social Security Area 1900-2080.” Actuarial Study No. 107, SSA Pub. No. 11-11536.
Bernard, Victor L., and Jacob K. Thomas. 1989. "Post-Earnings-Announcement Drift: Delayed Price Response or Risk Premium?” Journal of Accounting Research, 27: 1-36.

Campbell, John Y. 1991. "A Variance Decomposition for Stock Returns.” Economic Journal, 101(405): 157-79.

Campbell, John Y., and Robert J. Shiller. 1988. "The Dividend-Price Ratio and Expectations of Future Dividends and Discount Factors." Review of Financial Studies, 1(3): 195-228.

Costa, Dora L. 1999. "American Living Standards: Evidence from Recreational Expenditures." National Bureau of Economic Research Working Paper 7148.

De Bondt, Werner F. M., and Richard Thaler. 1985. "Does the Stock Market Overreact?" Journal of Finance, 40(3): 793-805.

DeLong, J. Bradford, Andrei Shleifer, Lawrence H. Summers, and Robert J. Waldemann. 1990. "Noise Trader Risk in Financial Markets." Journal of Political Economy, 98(4): 703-38.

DellaVigna, Stefano, and Joshua M. Pollet. 2005. "Attention, Demographics, and the Stock Market." National Bureau of Economic Research Working Paper 11211. 
DellaVigna, Stefano, and Joshua M. Pollet. 2007. "Investor Inattention and Friday Earnings Announcements." Unpublished.

Fama, Eugene F., and Kenneth R. French. 1992. "The Cross-Section of Expected Stock Returns." Journal of Finance, 47(2): 427-65.

Gabaix, Xavier, David Laibson, Guillermo Moloche, and Stephen Weinberg. 2006. “Costly Information Acquisition: Experimental Analysis of a Boundedly Rational Model." American Economic Review, 96(4): 1043-68.

Geanakoplos, John, Michael Magill, and Martine Quinzii. 2004. "Demography and the Long-Run Predictability of the Stock Market." Brookings Papers on Economic Activity, 1: 241-307.

Heuser, Robert L. 1976. "Fertility Tables for Birth Cohorts by Color." US Department of Health, Education, and Welfare. DHEW Publication 76-1152.

Hirshleifer, David, Sonya S. Lim, and Siew H. Teoh. 2004. "Disclosure to an Audience with Limited Attention.” Unpublished.

Huberman, Gur, and Tomer Regev. 2001. "Contagious Speculation and a Cure for Cancer: A Nonevent that Made Stock Prices Soar.' Journal of Finance, 56(1): 387-96.

Jegadeesh, Narasimhan, and Sheridan Titman. 1993. "Returns to Buying Winners and Selling Losers: Implications for Stock Market Efficiency." Journal of Finance, 48(1): 65-91.

Lakonishok, Josef, Andrei Shleifer, and Robert W. Vishny. 1994. "Contrarian Investment, Extrapolation, and Risk." Journal of Finance, 49(5): 1541-78.

Mankiw, N. Gregory, and David N. Weil. 1989. "The Baby Boom, the Baby Bust, and the Housing Market." Regional Science and Urban Economics, 19(2): 235-58.

Mankiw, N. Gregory, and Michael D. Whinston. 1986. "Free Entry and Social Inefficiency." RAND Journal of Economics, 17(1): 48-58.

Merton, Robert C. 1973. "An Intertemporal Capital Asset Pricing Model.” Econometrica, 41(5): 867-87.

Newey, Whitney K., and Kenneth D. West. 1987. "Hypothesis Testing with Efficient Method of Moments Estimation." International Economic Review, 28(3): 777-87.

Pagan, Adrian. 1984. "Econometric Issues in the Analysis of Regressions with Generated Regressors." International Economic Review, 25(1): 221-47.
Peng, Lin, and Wei Xiong. 2006. "Investor Attention, Overconfidence and Category Learning." Journal of Financial Economics, 80(3): 563602.

Poterba, James M. 2001. "Demographic Structure and Asset Returns." Review of Economics and Statistics, 83(4): 565-84.

Shleifer, Andrei. 2000. Inefficient Markets: An Introduction to Behavioral Finance. Clarendon Lectures in Economics. Oxford and New York: Oxford University Press.

Stambaugh, Robert F. 1999. "Predictive Regressions." Journal of Financial Economics, 54(3): 375-421.

US Department of Commerce, Bureau of the Census. Various years. Census of Manufacturers, Washington, DC: US Government Printing Office.

US Department of Commerce, Bureau of the Census. Various years. "Estimates of the Population of the US by Age, Sex, and Race," Current Population Reports, Series P-25 (Numbers 311, 519, 917, 965, and 985). Washington, DC: US Government Printing Office.

US Department of Health and Human Services, Public Health Service, Centers for Disease Control and Prevention, National Center for Health Statistics. 1996. Vital Statistics of the United States 1992: Natality, Vol. 1.

US Department of Labor, Bureau of Labor Statistics. 1983. Consumer Expenditure Survey, 1960-1961. ICPSR 9035. Inter-university Consortium for Political and Social Research.

US Department of Labor, Bureau of Labor Statistics. 1987. Survey of Consumer Expenditures, 1972-1973. ICPSR 9034. Inter-university Consortium for Political and Social Research.

US Department of Labor, Bureau of Labor Statistics, and United States Department of Agriculture, Bureau of Home Economics, et al. 1999. Study of Consumer Purchases in the United States, 1935-1936. ICPSR 8908. Inter-university Consortium for Political and Social Research.

Vuolteenaho, Tuomo. 2002. "What Drives FirmLevel Stock Returns?" Journal of Finance, 57(1): 233-64.

Watts, Ross L. 1978. "Systematic 'Abnormal' Returns after Quarterly Earnings Announcements." Journal of Financial Economics, 6(2/3): 127-50.

Weber, E. H. 1834. De Pulsu, Resorptione, Auditu, et Tactu. Annotationes Anatomicae et Physiologicae. Leipzig: Koehler. 